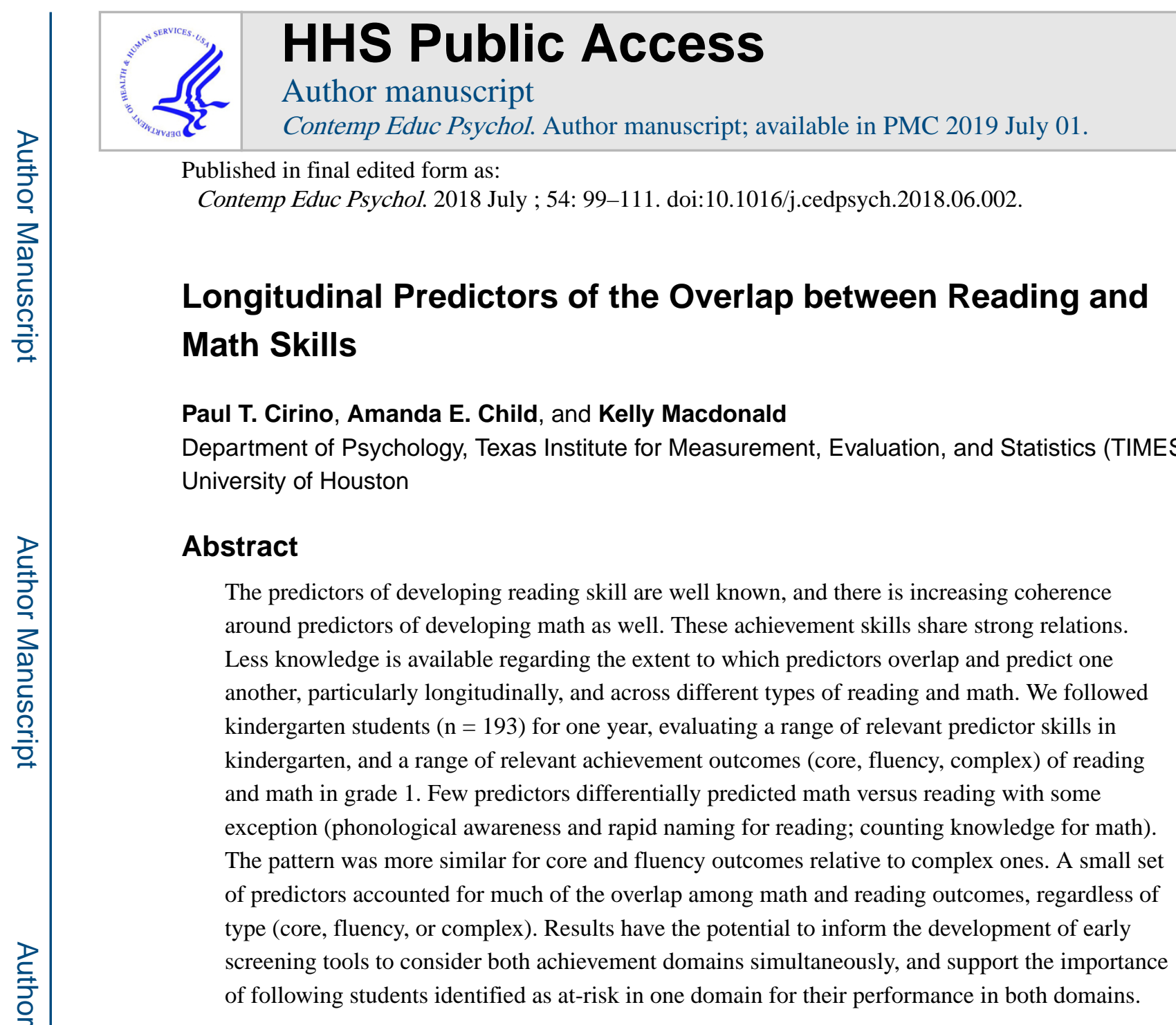

\title{
Keywords
}

math; reading; comorbidity; longitudinal; prediction

\begin{abstract}
Identifying early precursors of achievement is important because prevention and intervention programs are most cost-effective when delivered early, in both reading (Hollands et al., 2013) and math (Reynolds \& Temple, 2008). Reading and math difficulties are often comorbid (e.g., 30\% to 70\%; Badian, 1999; Kovas et al., 2007; Landerl \& Moll, 2010; White, Moffitt, \& Silva, 1992). Early predictors of math are increasingly represented in the literature, but early reading predictors are more established. Few experimenters have studied both academic skills (and their subskills), particularly longitudinally. In the current study, we focus on the relative roles of domain general and domain specific predictors measured in kindergarten, for multiple reading and math outcomes assessed at the end of first grade. Clarifying these roles may contribute to developing early identification strategies for students at-risk for problems in reading, math, or both.
\end{abstract}

Corresponding Author: Paul T. Cirino, Ph.D., Department of Psychology, Texas Institute for Measurement, Evaluation, and Statistics (TIMES), University of Houston, (832) 842-2002, pcirino@uh.edu. 


\section{Reading Predictors}

Reading is clearly tied to language skills. Specifically, phonological awareness (Hulme \& Snowling, 2009; Liberman, Shankweiler, Fischer, \& Carter, 1974; Vellutino, Fletcher, Snowling, \& Scanlon, 2004; Wagner \& Torgeson, 1987) is important for associating letters with the sounds they represent (the alphabetic principle; Liberman, Shankweiler, \& Liberman, 1989). Rapid naming invokes processes similar to those needed for reading (e.g., saccadic movements, shifting between and among orthographic and phonological representations) (Denckla \& Rudel, 1976; Norton \& Wolf, 2010; Wolf \& Bowers, 1999). Longitudinal research at early ages has provided robust support for these (Scarborough, 1998; Schatschneider, Fletcher, Francis, Carlson, \& Foorman, 2004) and other language skills (e.g., vocabulary, print awareness, letter identification, and decoding) as important early predictors of reading (Anthony \& Lonigan, 2004; Burgess \& Lonigan, 1998; Leppänen, Aunola, Niemi, \& Nurmi, 2008). Domain general predictors such as working memory (Savage, Lavers, \& Pillay, 2007; Siegel \& Ryan, 1989), processing speed (Shanahan et al., 2006; Willcutt et al., 2008), and attention (Grills-Taquechel, Fletcher, Vaughn, Denton, \& Taylor, 2013; Pham, 2016) also contribute to early reading. Predictors relate differentially to reading outcomes: rapid naming and processing speed are more related to reading fluency (Georgiou, Kirby, Parrila, \& Stephenson, 2008; Wolf, Bowers, \& Biddle, 2000), whereas working memory is more strongly linked with comprehension (Cain, Oakhill, \& Bryant, 2004; Carretti, Borella, Cornoldi, \& De Beni, 2009). Domain general factors account for small but relevant portions of variability in reading performance when proximal reading predictors are also considered (Cirino et al., 2018; Locascio, Mahone, Eason, \& Cutting, 2010; Cutting \& Scarborough, 2006).

\section{Math Predictors}

An array of potential early math predictors have been proposed, including numerosity, counting skill, behavioral inattention, and working memory. The term "numerosity" is used in several ways (Berch, 2005; Fuchs et al., 2010); Geary (2000) defines it as "the ability to determine accurately the quantity of small sets of items, or events, without counting." Numerosity is predictive of math performance across development (Butterworth, 2005; 2010; Geary \& vanMarle, 2016; Gersten \& Chard, 1999; Halberda, Mazzocco, \& Feigenson, 2008; Robinson, Menchetti, \& Torgesen, 2002), but a common distinction is between methods that focus on alphanumeric stimuli (symbolic) versus those that do not (nonsymbolic). The latter are consistently yet modestly related to written arithmetic ( $r=.22$; Chen \& Li, 2014), but symbolic measures have stronger relationships to math outcomes (Cirino, 2011; Holloway \& Ansari, 2009; Schneider et al., 2017; Vanbinst, Ansari, Ghesquiere, \& De Smedt, 2016).

Jordan and colleagues have utilized longitudinal methods to study precursors of early math proficiency (e.g. Hassinger-Das, Jordan, Glutting, Irwin, \& Dyson, 2014; Jordan, Kaplan, \& Hanich, 2002). For example, early number competencies (counting, number recognition, number comparison, nonverbal calculation, story problems, and number combinations) predict math performance and growth between first and third grade, over and above control variables (Jordan, Glutting, \& Ramineni, 2010). Moreover, a recent longitudinal study found 
that domain general abilities (i.e. working memory) were more important than domainspecific math skills in earlier grades but that general abilities and domain-specific knowledge contributed equally in later grades (Geary, Nicholas, Li, \& Sun, 2017), but reading achievement or its precursors were not included in these studies. Counting is a proximal skill for early written arithmetic (Geary, 2004), allowing more cognitive resources to be allocated to problem solving (Gersten \& Chard, 1999; Resnick, 1989). Math is related to both conceptual (Geary, Bow-Thomas, \& Yao, 1992; LeFevre et al., 2006) and procedural (Aunola, Leskinen, Lerkkanen, \& Nurmi, 2004; Geary, Hoard, \& Hamson, 1999; Aro, Eklund, Nurmi, \& Poikkeus, 2012) counting. Counting is often demonstrated orally, so it is not surprising that language relates to math, such as vocabulary (Geary, 2004; Koponen, Aunola, Ahonen, \& Nurmi, 2007), phonological processing (Fuchs et al., 2006; Hecht, Torgesen, Wagner, \& Rashotte, 2001; Krajewski \& Schneider, 2009), and rapid naming (Geary, Hoard, Byrd-Craven, Nugent, \& Numtee, 2007; Mazzocco \& Grimm, 2013).

Beyond language, other domain general factors such as working memory, processing speed, and attention also relate to math. Working memory allows for efficient resource allocation to arithmetic aspects of problem solving (Swanson \& Jerman, 2006), and is empirically linked to math performance (see Friso van den Bos, van der Ven, Kroesbergen, \& van Luit et al., 2013, for a meta-analysis). Processing speed improves the efficiency through which answers to familiar arithmetic problems are retrieved from long-term memory (Andersson \& Lyxell, 2007), and impacts the rate at which students count where needed, and/or impacts the rate of decay from working memory before finishing a problem (Fuchs et al., 2008; Geary, 1993). Attention also relates to math outcomes (Cirino, Fletcher, Ewing-Cobbs, Barnes, \& Fuchs, 2007; Fuchs et al., 2006; Fuchs et al., 2010); effective attentional allocation allows for efficient appraisal of problem components and retrieval of appropriate procedures (Fuchs et al., 2005).

As with reading, the relative strength of predictors for math varies depending on outcome. For math fluency, rapid naming and processing speed are stronger predictors than other domain general abilities (Koponen, Salmi, Eklund, \& Aro, 2013; Fuchs et al., 2006), whereas problem solving tasks have stronger associations with working memory (Fuchs et al., 2008, 2010; Swanson \& Beebe-Frankenberger, 2004). Domain general factors are more relevant for complex outcomes (i.e. word problems) relative to procedural computations (Fuchs et al., 2010).

In a prior study with this same sample (Martin, Cirino, Barnes, \& Sharp, 2014), our group examined several kindergarten predictors of various math outcomes (fluency, computation, and word problems) in first grade. Both math-specific predictors (symbolic number skills and counting) and domain general predictors (working memory and phonological awareness) were relevant; the impact of the latter was more prominent for math applications relative to math facts. That study, though, did not include reading outcomes or all the predictors considered here, nor did it address hypotheses about the impact of different kinds of predictors for reading versus math outcomes, relative to one another. 


\section{Reading and Math Overlap}

The studies above identify important cognitive skills that are predictive of early reading or math performance, considered separately. Yet, few experimenters have examined both reading and math outcomes and their overlap (e.g., the amount of variance that they share), and what factors may account for such overlap, and those that do vary in their approach.

Many cross-sectional studies of comorbid math and reading disability (MDRD) versus either reading disability (RD) or math disability (MD) include students in grade 2 or beyond (Child, Cirino, Fletcher, Willcutt, \& Fuchs, in press; Cirino et al., 2007; Moll, Göbel, Gooch, Landerl, \& Snowling, 2016; Moll, Göbel, \& Snowling, 2015; van der Sluis, de Jong, \& van der Leij, 2004; Willcutt et al., 2013). Findings from these studies are consistent with a multiple deficit model, which posits that comorbidity is the result of shared etiological factors, with unique etiological influences accounting for distinctions among disorders (Pennington, 2006). For instance, Willcutt et al. (2013) associated working memory, processing speed, and verbal comprehension with their comorbid group, whereas students with RD had unique impairments in phoneme awareness, rapid naming, and vocabulary, and those with MD showed set shifting impairments. Processing speed is an underlying risk factor for comorbid MDRD (Anderson, 2010; Willcutt, Sonuga-Barke, Nigg, \& Sargeant, 2008; Willcutt et al., 2010). Other studies are less consistent (Cirino et al., 2015; Moll et al., 2016), though the former group of studies employed more complex processing speed measures. Cirino et al. (2015) and Moll et al. (2016) both found support for working memory as an underlying risk factor for MDRD, with additional factors uniquely predicting reading and math skill.

Findings from longitudinal studies are also consistent with a multiple deficit model of comorbidity. For example, in a sample of first graders followed through fifth grade, Geary (2011) found that processing speed and the central executive component of working memory were predictors of both math and reading performance, with additional factors accounting for unique variance in each domain (i.e. phonological loop for reading, numerical competencies and visuospatial sketchpad for math). Reading predictors were not included. In longitudinal studies, Jordan and colleagues examined numerical competencies in students who struggle with both reading and math, but did not consider language or domain general predictors (Jordan \& Hanich, 2000; Hanich, Jordan, Kaplan, \& Dick, 2001; Jordan, Kaplan, \& Hanich, 2002; Jordan \& Hanich, 2003; Jordan, Hanich, \& Kaplan, 2003).

In some longitudinal studies, researchers have considered language skills as well as both reading and math performance in kindergarten-aged samples (Bramlett, Rowell, \& Mandenburg, 2000; Koponen et al., 2013). Bramlett et al. (2000) showed that symbolic representations (numbers and letters) were predictive of reading and math outcomes. Koponen et al. (2013) found that counting and rapid naming predicted both calculation and word reading, suggesting that both require fluently retrieving arbitrary associations between visual symbolic and phonological forms. These researchers, however, did not consider the role of other domain general factors. Recently, Korpipaa et al. (2017) used fluency-based reading and math outcomes to show that rapid naming, counting, letter knowledge, working 
memory, and nonverbal reasoning were predictive of reading and math overlap across grades 1 to 7 .

In a number of very large-scale longitudinal achievement studies, researchers have examined both domain general and domain specific factors from school entry to later grades. For instance, Duncan et al. (2007) found that the strongest predictors of math and reading performance were school-entry achievement levels, as well as behavioral inattention. By using large sample sizes in these and similar studies (i.e. Breslau, et al., 2010; Claessens \& Dowsett, 2014), researchers have focused less on individually administered cognitive individual difference variables, and have not explicitly addressed the overlap of math and reading outcomes.

\section{Summary}

In sum, few experimenters have considered both reading and math, and those that have are marked by heterogeneity in terms of design, grade level, scope of predictor set, and scope of outcome subskill (see Table 1). Therefore, the current study has potential to address this issue in a novel manner. Results of studies that do focus on both math and reading are consistent with the multiple deficit model of comorbidity. RD alone is associated primarily with phonological deficits but not numerosity, whereas MD alone is associated with both, though more uniquely for numerosity. Comorbid MDRD is characterized by a combination of these effects in an additive manner, with domain general factors most likely to have a shared role across domains. The most prominent of these include: (a) working memory (Child et al., in press; Cirino et al., 2015; DeWeerdt, DeSoete, \& Roeyers, 2013; Moll et al., 2016; Willcutt et al., 2013); (b) processing speed (Anderson, 2010; Willcutt, Sonuga-Barke, Nigg, \& Sargeant, 2008; Willcutt et al., 2010, 2013); (c) language-based skills (Cirino et al., 2015; DeWeerdt et al., 2013; Ostad, 2013; Mazzocco \& Grimm, 2013; Willcutt et al., 2013); and (d) attention (Breslau et al., 2010; Claessens \& Dowsett, 2014; Duncan et al. 2007; Steele, Karmiloff-Smith, Cornish, \& Scerif, 2012). However, the relative size of these effects is not entirely consistent.

The above review suggests that a constellation of domain general factors seems to be differentially predictive of the overlap of reading and math outcomes; however, authors of most predictive studies of comorbidity have evaluated only one type of skill (i.e. decoding for reading, computation for math). In the separate math and reading literatures, rapid naming and processing speed have stronger links to both math and reading fluency than other achievement outcomes (Fuchs et al., 2006; Georgiou, Parrila, Kirby, \& Stephenson, 2008; Koponen et al., 2013; Wolf, Bowers, \& Biddle, 2000). There are greater contributions from working memory and language processes (i.e. phonological awareness) for more applied tasks (e.g., word problems; Cain, Oakhill, \& Bryant, 2004; Carretti, Borella, Cornoldi, \& De Beni, 2009; Swanson \& Beebe- Frankenberger, 2004).

\section{Present Study and Hypotheses}

We examined predictors with relevance to reading and/or math, and evaluated both types of outcomes. In the context of prior findings, we made hypotheses about the relative roles of the set of potential predictors for reading versus mathematics, and their subskills, over time, 
in young children. Most researchers have focused on decoding and computations, respectively, and we refer to these as "core" outcomes. For this core pairing, we expected well-known language variables (phonological awareness, rapid naming, vocabulary) to be more strongly related to reading than to math; this may seem self-evident but as noted above, several of these relate to math as well. We expected that number skills (number identification, symbolic comparison, counting) would be more strongly related to computations than decoding. We expected broader skills (such as nonverbal reasoning, working memory, and attentional behavior) to be important for both decoding and computation, but predicted that nonverbal reasoning and working memory would have stronger relations to computation relative to decoding. We expected the contribution of these domain general skills to be less than domain-specific predictors. In corollary, we also hypothesized about the factors relevant to the overlap of reading and mathematics (those that account for variance between these outcomes). We expected that a combination of the above skills would account for that relationship, in line with multiple-deficit models of shared cognitive risk factors. In general, the more differentially predictive is a variable, the less we expected that variable to account for overlap across achievement domains. For example, we expected number skills to more strongly predict computations versus decoding, but expected these cognitive skills to contribute less to the overlap between outcomes, relative to domain general skills that impact both outcomes similarly (i.e., attention).

There is less guidance from the literature regarding other math and reading subskill pairings, but we do expect some variation. For fluency (reading fluency and math fluency), the impact of rapid naming is likely greatest, and should contribute strongly to overlap, even relative to processing speed (measured in a discrete rather than complex manner). Overlap will likely also be strong for number identification given its close alignment with naming stimuli. For more complex skills (reading comprehension and problem solving), we expect that a broader range of predictors will account for the overlap, and do so equivalently.

\section{Methods}

\section{Participants}

An existing study that began with 286 kindergarten students from eight schools and 37 classrooms (mean age $=6.2, S D=0.3$ ) served as the larger data source (Cirino, 2011). The 193 participants (49\% female) in the current study were those who were evaluated in kindergarten as well as grade 1 (mean age $=7.2, S D=0.3$ ). Students were diverse in ethnicity and SES, with minimal differences between students who were unavailable in Grade 1 compared to those who were; full demographic characteristics appear in an earlier, different study focused only on mathematics but with this same sample (Martin et al., 2014). Participants exhibited good math and reading skills overall (mean standard score of 109 for WJ-3 Calculation; standard score of 113 for WJ-3 Letter Word Identification).

\section{Procedures}

Following school approval, institutional review board approval from the authors' university, and parent consent and student assent, students were assessed in their schools, typically on two consecutive days in two 30-minute sessions. Assessments were conducted in Spring of 
kindergarten and again in the Spring of first grade. Psychometric properties were adequate, as indicated below, with details regarding the kindergarten assessments appearing in Cirino (2011). Reliabilities of the measures used in the current study appear in Table 2.

\section{Measures}

We administered 32 measures, but for parsimony, we analyzed 17 variables by creating composites based on relations derived from confirmatory factor analyses and structural equation modeling from prior work (Cirino, 2011); these 17 variables can be grouped into domain specific predictors (four for math and three for reading), domain general predictors (four), and outcomes (three each for math and reading). Further details of most predictor measures are available in Cirino (2011), with measures specific to this study described below. Analyzed variables are underlined. In general, predictor measures were administered in kindergarten, and outcome variables were administered in grade 1.

Domain Specific Math Predictors-Rote Counting includes three tasks; students count aloud from 1 to 100 (see Clarke \& Shinn, 2004, for a similar task), or count down from 10 to 1 and from 20 to 1 . Each task is converted to an index of correct responses per second.

Counting Knowledge has two tasks. First, children are shown five pictures of cars and boxes randomly arrayed and were asked to count aloud, with the key index being the total number of errors across all error types (one-to-one, stable order, abstraction, and cardinal). The second task was the error count trials from the Puppet Counting task (Geary, Brown, \& Samaranayake, 1991; Geary, Hamson, \& Hoard, 2000). Symbolic Comparison also has two tasks; first, students are shown six pairs of Arabic numerals and are asked to choose the larger number. The second task is AIMSweb Quantity Discrimination (Clarke \& Shinn, 2004), where students circle the larger number in 28 pairs of numbers in a 1-min time limit (correct minus incorrect responses). Finally, for Symbolic Labeling, students name 15 single, two, and three digit numbers.

Domain Specific Reading Predictors-Phonological Awareness uses raw scores of the Blending Phonemes and Phoneme Elision tasks from the Comprehensive Test of Phonological Processing (CTOPP; Wagner, Torgesen, \& Rashotte, 1999). For Rapid Automatized Naming (RAN), students view and quickly identify familiar target stimuli arranged in rows as quickly as possible; portions of the Rapid Letter Naming, Rapid Digit Naming, and Rapid Object Naming subtests (one trial instead of two) of the C-TOPP (Wagner et al., 1999) were used, converted to items per second. Finally, Vocabulary is a receptive measure where students identify pictures from among distractors, corresponding to a word/phrase spoken by the examiner, and is component of the Verbal Knowledge subtest of the Kaufman Brief Intelligence Test-2 (KBIT-2; Kaufman \& Kaufman, 2004). We used raw scores as the metric to be consistent with other predictors, and this is the only predictor measure administered in Grade 1 rather than kindergarten.

Domain General Predictors-Processing Speed included two subtests of the Underlining Task, where students underline all instances of a target (" 4 " or “+”) from among distractors; score was the correct targets for each subtest in 30 seconds. These two subtests correlated $r=.52$ in the full kindergarten sample. Spatial Working Memory is a "span" 
measure requiring processing of a shape (whether or not it is a star), while recalling sequential locations of the shapes; the score is the number of correct sequences (out of 12). Nonverbal Reasoning was obtained via the raw score (to be consistent with other predictors) from the Matrices subtest of the KBIT-2 (Kaufman \& Kaufman, 2004). Finally, Behavioral Inattention was obtained from the Inattention subscale of the teacher-rated Strengths and Weaknesses of ADHD and Normal Behavior (SWAN; Swanson et al., 2012); nine items are rated -3 to +3 , with negative scores corresponding to problems.

Math and Reading Outcomes-As with predictors, composites were formed, though these measures were standardized based only on the first graders of the present study (this was the only time they were administered). Key measures included standard scores from subtests of the Woodcock Johnson -Third (WJ-III) Edition (Woodcock, McGrew, \& Mather, 2001), and the Wide Range of Achievement Test-Third (WRAT-3) Edition (Wilkinson, 1993), and were paired based on the type of skill addressed.

For the first pair (core skills), Reading Decoding included the WJ-III Letter Word Identification, WRAT-3 Reading, and WJ-III Word Attack subtests. For the first two tasks, students identify letters followed by real words, and for the third task, students pronounce regular nonwords. Computation included the WJ-III Calculations (Woodcock et al., 2001) and WRAT-3 Arithmetic subtests (Wilkinson, 1993). For Calculations, participants in this age range solve single- and multi-digit addition and subtraction problems, whereas for Arithmetic, participants complete items related to early number identification, counting, and number comparisons, followed by written arithmetic increasing in difficulty.

For the second pair (fluency), Math Fluency includes total raw scores (correct minus incorrect) for Small Sums Addition and Small Sums Subtraction, where students complete as many single-digit addition or subtraction problems as possible, respectively, in 2 minutes. For Reading Fluency, students to read as many real words as possible in 45 seconds for the TOWRE Sight Word Efficiency task (Torgesen, Wagner, \& Rashotte, 1999); standard scores were used in analyses. This was combined with Oral Reading Fluency subtests from the Dynamic Indicators of Basic Early Literacy Skills (DIBELS; Good, Gruba, \& Kaminski, 2002); students read two short passages aloud for 1 minute each.

Finally, for the last pairing (complex skills), Math Problem Solving includes the WJ-III Applied Problems (Woodcock et al., 2001) subtest standard score, with a variety of tasks (naming, telling time, counting, word problems) of increasing difficulty. This was combined with the total raw score of Single Digit Story Problems (Riley, Greeno, \& Heller, 1983; adapted by Hanich et al., 2001) that includes 14 change, combine, and compare addition and subtraction problems read aloud by the examiner. Finally, Reading Comprehension was assessed with standard score of the WJ-III Passage Comprehension and raw score of AIMSweb Reading Mazes (Shinn \& Shinn, 2002). For Passage Comprehension, children initially identify rebuses that correspond to pictures, or pictures correspond to words; as the task progresses, children complete a cloze-type passage. For Reading Mazes, students have three minutes to read a 150-400 word passage, but after the first sentence, for every seventh word, children must choose the correct target word from three options. 
Because the reading and math outcomes have not been examined together, we ran a confirmatory factor analyses on these measures, to help justify the compositing of these outcomes. This model, with all 13 achievement measures and six latent variables, showed a good data fit (e.g., $\chi^{2}(50)=95.94, p=.0001$; comparative fit index $=.98$; root mean squared error of approximation $=.069$; standardized root mean residual $=.023$ ).

\section{Analyses}

We used multivariate regression and partial correlation analyses to assess the relationships between cognitive and academic variables. Multivariate analyses allow us to determine if a given predictor is differentially predictive of one outcome versus another; in other words, if a particular cognitive ability more strongly contributes to one outcome versus another. For this study, we compared the degree to which each cognitive variable predicted reading versus math outcomes within each domain pairing (i.e., core skills, fluency, and complex skills). Partial correlation analyses allow us to assess the degree to which a given predictor accounts for overlap of a pair of academic skills, or how important a given predictor is for variance that is shared between two outcomes.

Examination of the variable distributions did not reveal anomalies, and normality tests (Shapiro-Wilk) were not significant, consistent with Q-Q plots indicating normal distribution of the residuals. Tolerance statistics were uniformly low, indicating no concerns for multicollinearity. Analyses were conducted with and without high influence outliers and were largely similar. Results below are shown with outliers excluded, with notations where there were differences.

Demographic variables were considered as relevant covariates. Race/ethnicity, sex, age, primary language, and socioeconomic status (as determined by free lunch status) were evaluated (Kao \& Thompson, 2003; Ladson-Billings \& Madison, 1997; Lubienski, 2002; McGraw, Lubienski, \& Strutchens, 2006; Tate, 1997). All correlated with one or more predictor or outcome variable, although including covariates rarely affected substantive results. For clarity, results presented below do not include covariates, though notation is made where their inclusion made a difference.

Correlations between the 17 analyzed (individual or composite) measures appear in Table 3 . Composites were created by standardizing the raw score of each measure against the original kindergarten sample; these subtest z-scores were then averaged. Means and standard deviations of the composites appear in Table 3. Note that because the standardization of predictors utilized a larger sample, means are not exactly zero, although their range was only $\mid 0.00$ to $0.15 \mid$, affirming that the subset of participants used in the present study were representative of the overall sample. Table 3 also presents zero-order correlations among all measures. Preliminary results (i.e., zeroorder correlations) are presented, followed by overlap results (multivariate regressions and partial correlations), first for the core outcomes (decoding and computation), and then for fluency and complex outcomes. 


\section{Results}

Preliminary results of Table 3 show that correlations among outcome variables were positive and significant $p<0.001$, and strong (range $r=0.55$ to 0.67 , median $r=0.61$ ). Further,

Supplementary Tables S1 and S2 present univariate results (the same results in two formats: by outcome and by predictor, respectively) and show that the set of predictors strongly contributed to all outcomes (all $p<0.001 ; R^{2}$ range $=0.48$ to 0.68 ), with differential contributions of individual predictors across outcomes.

\section{Multivariate Multiple Regression-Preliminary Analyses}

Multivariate multiple regression analyses compared the contribution of predictors across outcomes within a single model (six outcome variables and 11 predictors). This was done in three stages. First, we evaluated whether a given predictor's effect (coefficient) significantly differed across the six outcomes (a test with six degrees of freedom). This broadly determined if a predictor equally predicted all six outcomes or not. Then, we determined whether a given predictor's effect for all three math outcomes collectively was different than its effect for all three reading outcomes (a test with one degree of freedom), which elucidated if a predictor was broadly more predictive of math versus reading. Finally, we compared predictors across specific pairs of outcomes to determine if a predictor was more predictive of a specific math versus reading outcome (i.e., decoding versus computation; results described in the next section). Results for the first two stages appear in Table S3. For seven of the 11 predictors, their coefficients differed across all six outcomes, and four of 11 differed between math and reading; three predictors (phonological awareness, rapid naming, and working memory) had differences for both sets of contrast (see Table S3).

With regard to broad math versus reading comparisons, results of this overall model showed that counting knowledge, $F(1,160)=8.24, p=0.005$, and working memory, $F(1,160)=4.04$, $p=0.046$, more strongly predicted all math versus all reading outcomes, whereas phonological awareness, $F(1,160)=6.23, p=0.014$, and rapid naming, $F(1,160)=21.05, p$ $<0.001$, more strongly predicted all reading as compared to all math outcomes. Of note, with covariates in the model, working memory was no longer significantly differentially predictive of math versus reading, $F(1,155)=3.62, p=0.059$. Furthermore, when outliers were included, symbolic comparison, $F(1,166)=4.53, p=0.035$, and vocabulary, $F(1,166)=$ $4.02, p=0.047$, differentially predicted math versus reading outcomes, and working memory did not, $F(1,166)=3.62, p=0.059$. Although $p$ values changed slightly, the overall substantive changes due to covariates or outliers were small.

\section{Multivariate Multiple Regression-Pairwise Analyses}

However, the above results do not allow us to answer specific questions regarding whether a given predictor had different effects for a specific pair of outcomes (core, fluency, and complex), which is how hypotheses were framed. Therefore, we subsequently ran more constrained multivariate contrasts to assess the strength of a given predictor variable to a given type of math versus reading outcome, controlling for other predictors, and considering all outcomes (as the contrasts occurred within the overall model). These results appear in Table 4. 
For the core comparison (decoding versus computation), language-related variables (phonological awareness, rapid naming) were more strongly predictive of decoding than computation (phonological awareness, $p=0.026$; rapid naming, $p<0.001$ ). To illustrate, the multivariate contrast between decoding and computation is significant for phonological awareness $(F=5.07, p=0.026)$, and referring to Table $\mathrm{S} 2$, phonological awareness significantly predicts decoding $(b=0.31, p<0.001)$ but does not significantly predict computation ( $b=0.11, p=0.158$ ). Given that the standardized beta value is higher for decoding as compared to computation, results for this contrast affirm that phonological awareness more strongly predicts decoding as compared to computation. Conversely, counting knowledge was more strongly predictive of computation than decoding, $p=0.012$. None of the other predictors had a differential effect for this core comparison.

For the fluency comparison (reading fluency versus math fluency), results were similar, with phonological awareness, $p=0.030$, and rapid naming, $p<0.001$, more strongly predictive of reading versus math fluency, and counting knowledge more strongly predictive of math versus reading fluency, $p=0.027$. None of the other predictors had a differential effect for math versus reading fluency.

Results varied more for the complex comparison. Rapid naming was again more predictive of reading comprehension versus problem solving, $p=0.023$, and counting knowledge was more predictive of problem solving versus reading comprehension, $p=0.034$. Unexpectedly, though, vocabulary more strongly predicted problem solving relative to reading comprehension, $p=0.002$. Other predictors (including phonological awareness) where not differentially predictive.

Analyses that included covariates, and/or included outliers, did not result in substantive changes for core comparisons, and including covariates did not change results for the complex pairing. However, with covariates in the model, phonological awareness did not more strongly predict reading fluency as compared to math fluency. In addition, when outliers were not excluded, symbolic comparison more significantly predicted math fluency versus reading fluency, and rapid naming was no longer differentially predictive reading comprehension versus problem solving.

\section{Partial Correlation Analyses}

To address the hypotheses regarding variance shared between pairs of outcomes (their overlap), partial correlations were calculated (see Table 5). Consistent with hypotheses, partialling all predictors from any pair of outcomes accounted for large proportions of the variance shared between the two outcomes, ranging from a 75\% reduction in the variance shared between fluency skills, to a $91 \%$ reduction in variance shared between complex skills. To illustrate, decoding and computation correlate 0.67 , corresponding to an $R^{2}$ value of 0.44 (44\% shared variance). After partialling all predictors, this correlation decreases to 0.33 , corresponding to an $R^{2}$ value of 0.11 and a percent change in $R^{2}$ of $75 \%$ (or ( $0.11-$ $0.44) / 0.44$, described as a $75 \%$ reduction in variance shared).

For the primary pairing (core skills, decoding versus computation), the hypothesis that their overlap would be most strongly accounted for by language variables followed by number- 
related variables and then broad skills was generally supported. Specifically, phonological awareness strongly contributed to the overlap of core academic skills ( $R^{2}$ reduction of $48 \%$ ) while rapid naming contributed more modestly to the overlap ( $R^{2}$ reduction of $\left.25 \%\right)$. Neither variable uniquely predicted computation in multivariate analyses, however (See Tables S1 and S2). Symbolic naming also contributed strongly to the overlap between outcomes (reduction in $R^{2}=66 \%$ ), and equally and significantly predicted both outcomes in univariate and multivariate analyses (Tables S1 and S2, and 4). Vocabulary did contribute to the overlap between the outcomes ( $R^{2}$ reduction of $25 \%$ ), though was not a unique contributor to either outcome (Tables S1 and S2).

Rote counting also accounted for variance shared between core academic skills, as it reduced $R^{2}$ by $30 \%$, despite that it did not uniquely predict either outcome in univariate analyses (Tables S1 and S2). Counting knowledge only subtly contributed to the overlap between outcomes (reduction in $R^{2}=11 \%$ ), and was significantly predictive of computation (Tables S1 and S2). Symbolic comparison contributed more strongly to the overlap in computation and decoding (reduction in $R^{2}=32 \%$ ), with significant unique relations to computation.

Contrary to expectations, processing speed and working memory were not strong contributors to the overlap of core skills of single-word reading and computations (reduction in $R^{2}=5 \%$ and $11 \%$, respectively). Nonverbal reasoning and attention contributed more strongly to the overlap, with $20 \%$ and $25 \%$ reductions in $R^{2}$, respectively. However, no domain general variables uniquely predicted either decoding or computation (Tables S1 and S2).

Results for other outcome pairings (fluency and complex skills) were generally consistent with hypotheses. As expected, we found that rapid naming strongly contributed to the overlap in reading and math fluency, accounting for 50\% of shared variance. However, in contrast to expectation, processing speed contributed negligibly to the reduction in shared variance in the fluency pairing. Also, rapid naming was not the strongest contributor to the overlap between the fluency outcome pairing; rather, symbolic naming was, and this variable reduced the overlap by a notable $75 \%$.

Contrary to our hypothesis that a broader range of skills would account for overlap between complex skills, the same predictors important for core skills and for fluency also contributed to the overlap between complex academic skills. Of note, however, these skills collectively accounted for 3 to $17 \%$ more overlap among complex outcomes on average, relative to core or fluency outcome pairings.

Broadly, the above results point to a small number of predictors (phonological awareness, rapid naming, and symbolic naming) that seem to account for most of the overlap between pairs of outcomes. In post-hoc follow up analyses, partialling only these three predictors (Table 5) accounted for nearly all of the reduction in variance that was initially accounted for by partialling all predictors. Other predictors that contributed to overlap in earlier analyses included attention and nonverbal reasoning, and counting knowledge was the most specific predictor for math skills. However, partialling these predictors in addition to symbolic naming, phonological awareness, and rapid naming only accounted for a further 5\% 
reduction in shared variance for complex skills, and no additional variance for core or fluency skills.

\section{Discussion}

The goal of the present study was to clarify longitudinal shared and unique influences on the overlap of young students' reading and math performances. The results suggest four broad points. First, predictors were only occasionally differentially predictive of one academic skill but not the other. However, where differentiation occurred, it occurred in the hypothesized direction, with counting knowledge more strongly related to math, and phonological awareness (PA) and rapid automatized naming (RAN) more related to reading. Second, accounting for all predictors strongly diminished (though did not eliminate) variance shared between reading and math outcomes. Third, a small set of predictors (symbolic naming, PA, RAN) accounted for nearly the same amount of overlap as all predictors together, and these were predominantly linguistic in nature, even where they were numerically focused (e.g., symbolic naming). Finally, the pattern of differential prediction findings were more similar for core and fluency outcomes relative to complex outcomes, but the extent to which predictors accounted for math and reading overlap were similar across all three pairings. Overall, results imply that it may be feasible to screen for difficulties in both areas/subareas simultaneously and efficiently, and that when difficulties in one achievement domain appear, it is important to monitor the other achievement domain.

We hypothesized that PA and RAN would affiliate more with reading relative to math, and conversely that number skills would be more strongly associated with math, though to a lesser degree. This hypothesis was generally supported. It is not at all surprising that PA and RAN were more strongly associated with decoding skills than computations, given the maturity of the literature that causally implicates these skills for reading (Denckla \& Rudel, 1976; Liberman, Shankweiler, Fischer, \& Carter, 1974). Further, neither PA nor RAN were unique predictors of any math outcome in when all predictors were included in the model (Tables S1 and S2). However, such findings should not be taken to mean that such skills are unrelated to early math skill, as both PA and RAN are moderately correlated with all three math outcomes, likely due to the role of language in learning and retrieving math facts (Fuchs, Geary, Fuchs, Compton, \& Hamlett et al., 2016; Koponen et al., 2007). In addition, PA and RAN were also related to specific number-based predictors, as well as to most domain general predictors (see Table 3 zero-order correlations). Taken together, the pattern offers some insight into inconsistencies in the literature, where some researchers show strong predictive power for PA and RAN (Cirino, 2011; Martin et al., 2014; Mazzocco \& Grimm, 2013), and others finding far less support (Passolunghi, Vercelloni, \& Schadee, 2007). Both statements are true, and different results will manifest depending on the comprehensiveness of prediction models.

For math-specific variables, we expected the number and strength of numerosity variables to be smaller relative to that of PA and RAN for reading, and this was indeed the case. The only number-specific predictor to differentially predict math more than reading for all three pairings (core, fluency, complex) was counting knowledge, which also happened to have the weakest relations with PA and RAN (see Table 3). Again, such results do not imply that 
number predictors are not important, but rather that few such number-based predictors are separable from their language components. Thus, it is not surprising that these predictors were also moderately to robustly related to decoding performance (see Table 3 ). In particular, symbolic naming (identifying Arabic numerals) was the single most relevant predictor in terms of accounting for the overlap between all math and reading pairs. These results reinforce a theme in the literature on the prediction of early scholastic math skills - a wide range of potential factors are shown to be relevant (Cirino, 2011; Geary, 2004; Jordan et al., 2009), though few stand out to the extent that PA and RAN do with regard to developing decoding skill. At least one group (Vanbinst et al., 2016) has argued that symbolic comparison may in fact play such a role, though the present results would suggest that at least concerning the overlap of reading and math, that it is perhaps not symbolic comparison per se that is most relevant, but the symbolic naming prerequisite of such comparisons.

Beyond the above "domain-specific" skills that have been closely associated with reading or math, domain general skills including processing speed and attention have been linked to both reading and math. Working memory, nonverbal reasoning, and vocabulary have been linked to both as well, though the former two moreso with math, and vocabulary moreso with reading. Because we expected that such domain general skills would be similarly predictive of both math and reading, we also presumed that they may also account for the overlap of each pair of achievement skills. However, as indicated above, language-based predictors (including symbolic naming) not only showed the strongest relation to all outcomes relative to any other predictors, but also managed to be differentially (preferentially) related to reading versus math.

Among domain general skills, only attentional behavior and nonverbal reasoning contributed to the overlap of basic skills - each of the others did little to diminish the relation of decoding with computation. Interestingly, none of the domain-general skills held unique predictive ability in the context of the stronger domain-specific predictors, for either decoding or computation. With the exception of processing speed, each of these skills showed significant zero-order correlations with both decoding and computation (median $r$ $=.27,8$ correlations), and similarly sized correlations with one another (see Table 3 ). More interesting is that (again with the exception of processing speed), these domain general variables showed relatively similar, and stronger, relations with the domain-specific predictors from both math and reading (median $r=.42,24$ correlations), with the strongest of these for attentional behavior (median $r=.48,6$ correlations). The results suggest that the effect of these domain general skills is likely indirect, via more proximal predictors. This was also suggested using the kindergarten data from the larger parent sample (Cirino, 2011), but in the present study, we suggest that this may also be true for a wider range of outcomes, even when measured at a later point in time. Similarly, LeFevre et al. (2010) have posited that general cognitive skills influence math outcomes via measures of early numeracy knowledge. Clarifying the roles of domain general predictors would be most strongly answered with a design that more deliberately sets out to establish such mediational effects by measuring domain general skills quite early (e.g., preschool), followed by proximal predictors later, yet still early in the educational sequence (e.g., kindergarten), followed by growth in decoding and computational skills throughout elementary development. 
That processing speed related weakly to all other predictors and outcomes (median $r=.16$, 10 correlations) reiterates the need to distinguish between simple and complex processing speed (Child et al., in press; Gerst, Cirino, Miciak, Yoshida, Gibbs, \& Woods, 2018; Jacobson et al., 2017; Willcutt et al., 2013). More complex processing speed measures are more likely to uniquely predict outcome overlap, though this has yet to be empirically tested in the context of the range of domain-specific predictors, as evaluated here.

To date, wherever math and reading outcomes have been compared, researchers have most often centered on the core decoding-computation pairing (Cirino et al., 2015; Mazzocco \& Grimm, 2013; Moll et al., 2015; though see Korpipaa et al., 2017 for a recent example focused on fluency). Therefore, we had fewer hypotheses about other reading-math combinations, and we generally found that fluency and complex outcome pairs were similar with regard to cognitive variables that contributed to their differential and shared prediction. For both fluency and complex outcome pairs, counting knowledge more strongly predicted math outcomes (math fluency and problem solving) relative to reading, and rapid naming more strongly predicted reading fluency and comprehension versus their math counterparts. Vocabulary was also differentially predictive of math problem solving relative to reading comprehension. In line with others (Fuchs et al., 2010; 2012), math problem solving, though not reading comprehension, had a wider range of unique predictors relative to core skills, even though recent studies do implicate a wide range of predictors of all types of reading (Cirino et al., 2018).

Our findings suggest that a small set of predictors (PA, RAN, and symbolic naming) could go a long way towards effectively screening for difficulty in both reading and math. Via post-hoc analyses, we showed that this set of three predictors was almost as powerful as the full set of predictors in explaining the overlap among all three pairs of math and reading outcomes. Given such results, it may be that this small set of predictors is as effective as this study's full set of predictors at predicting risk for developing reading or math difficulties as well. This may be likely, given the consideration of achievement across a continuum rather than as pure categories, in line with other recent work (Child et al., in press; Cirino et al., 2015; Branum-Martin et al., 2013; Swanson, Orosco, \& Kudo, 2017). Authors of future studies might evaluate this directly, not only at early stages, but later in school as achievement skills diverge (e.g., decoding unfamiliar words, versus subtraction), or after which they become more automatized, later in elementary school (Chall, 1983; Yovanoff, Duesbery, Alonzo, \& Tindal, 2005).

One aspect of the present study that remains unclear is how well the current measure of symbolic number naming would continue to exert influence if it were in the context of a letternaming task. It is likely that such measures would show considerable relations to one another. For example, Geary and vanMarle (2016) found a strong correlation $(r=.71)$ between number and letter identification, and measures of rapid letter naming and rapid digit naming also correlate quite strongly with one another (Wagner et al., 1999; Norton \& Wolf, 2012). Measures of digit span and letter span also correlate strongly (Reynolds \& Bigler, 1994). Thus, the effectiveness of the symbolic number naming task, as used here, may have more to do with the underlying ability to associate phonological representations ("seven"; "kay") to an arbitrary symbol ("7"; "K"), which are in turn associated with other 
representations, symbols, and semantic meanings (Holloway, Battista, Vogel, \& Ansari, 2013). To develop early achievement skills, children need a foundation of core knowledge upon which to build. Identification of letters and numbers by their alphanumeric symbol may provide such a foundation. This information is typically learned via both informal and formal processes, even prior to school (e.g., parents pointing out letters or numbers, playing with blocks or puzzles involving them). Additional informal skills include nonverbal arithmetic for math (Jordan et al., 2002) and picture book experience for reading (e.g., Lonigan, Burgress, \& Anthony, 2000; Sulzby, 1985; Whitehurst \& Lonigan, 1998). We expect that the pattern of results obtained here would still manifest if we had available a letter identification measure instead of a numerical identification measure (or if both were present). Either measure is likely to tap the essential process of associating a written symbol with a name, sound, and meaning. This is likely to assist in the transition from oral and/or informal arithmetic to that which comes to rely more extensively on "graphemes" (e.g., written arithmetic). It is understood that although PA and RAN are strong predictors of reading, identification of letters is also a crucial skill (Burgess \& Lonigan, 1998; Leppänen et al., 2008; Lonigan et al., 2000).

\section{Limitations}

Our findings should be considered in light of a few limitations. Although our study was longitudinal, having math and reading outcome measures throughout the elementary school years in addition to kindergarten- $1^{\text {st }}$ grade would have provided a clearer understanding of how this array of predictors relates to the overlap of reading and math across early development. Moreover, with access to measures of domain general predictors in pre-K, we could have examined the indirect role of these skills in relation to more proximal domain specific predictors as measured in kindergarten. Additionally, as discussed above, we could have further delineated the role of attributing phonological representations to alphanumeric stimuli in both math and reading outcomes with the addition of a letter identification task. In regards to our domain general predictors, using a complex processing speed task in addition to our simpler task would have allowed us to better understand this construct's role in the math/reading overlap in the context of a wide range of predictors. Finally, studying a specific at-risk sample may have yielded different results, though because reading and math are continua, there is weak evidence to suggest that the suite of predictors for these skills would differ. These limitations might provide impetus for future studies.

\section{Conclusions}

The present study is one of only a few to examine the relative contributions of a wide array of predictors for three types of math and reading outcomes in first grade. We build upon past studies of early math and reading development by clarifying the role of early linguistic skills for both reading and math achievement, while also highlighting differential prediction supporting multiple-deficit models of shared cognitive risk factors. Because many of these predictors are related, the pattern of unique effects observed here has rarely been demonstrated previously. We suggest that measuring a few such skills (phonological awareness, rapid naming, symbolic naming) may be sufficient for identifying students at risk for problems in both domains, and suggests that children who are at-risk or struggling in one domain should also be closely monitored for difficulties in the other domain. 


\section{Supplementary Material}

Refer to Web version on PubMed Central for supplementary material.

\section{Acknowledgments}

This work was supported by Grant HD050422 from the National Institute of Child Health and Human Development (NICHD) awarded to the University of Houston. The attitudes and opinions expressed in this article are those of the author and do not necessarily reflect those of the NICHD or of the National Institutes of Health. The author thanks Maria Hernandez, the school personnel, and especially the students who made this research possible.

\section{References}

Anderson JD, Wagovich SA. 2010; Relationships among linguistic processing speed, phonological working memory, and attention in children who stutter. Journal of Fluency Disorders. 35(3):216234.https://doi.org/10.1016/j.jfludis.2010.04.003 [PubMed: 20831969]

Andersson U, Lyxell B. 2007; Working memory deficit in children with mathematical difficulties: A general or specific deficit? Journal of Experimental Child Psychology. 96(3):197-228.https:// doi.org/10.1016/j.jecp.2006.10.001 [PubMed: 17118398]

Anthony JL, Lonigan CJ. 2004; The nature of phonological awareness: Converging evidence from four studies of preschool and early grade school children. Journal of Educational Psychology. 96(1): 43.http://dx.doi.org/10.1037/0022-0663.96.1.43

Aro T, Eklund K, Nurmi J-E, Poikkeus A-M. 2012; Early language and behavioral regulation skills as predictors of social outcomes. Journal of Speech, Language, and Hearing Research. 55(2):395-408. DOI: 10.1044/1092-4388(2011/10-0245)

Aunola K, Leskinen E, Lerkkanen M-K, Nurmi J-E. 2004; Developmental dynamics of math performance from preschool to grade 2. Journal of Educational Psychology. 96(4):699.http:// dx.doi.org/10.1037/0022-0663.96.4.699

Badian NA. 1999; Persistent arithmetic, reading, or arithmetic and reading disability. Annals of Dyslexia. 49(1):43-70.

Bramlett RK, Rowell RK, Mandenberg K. 2000; Predicting first grade achievement from kindergarten screening measures: a comparison of child and family predictors. Research in the Schools. 7(1):1-9.

Breslau N, Breslau J, Peterson E, Miller E, Lucia V, Bohnert K, Nigg J. 2010; Change in teachers' ratings of attention problems and subsequent change in academic achievement: a prospective analysis. Psychological Medicine. 40(01):159-166.https://doi.org/10.1017/S0033291709005960 [PubMed: 19490743]

Burgess SR, Lonigan CJ. 1998; Bidirectional relations of phonological sensitivity and prereading abilities: Evidence from a preschool sample. Journal of Experimental Child Psychology. 70(2):117141.https://doi.org/10.1006/jecp.1998.2450 [PubMed: 9729452]

Butterworth B. 2005; The development of arithmetical abilities. Journal of Child Psychology and Psychiatry. 46(1):3-18. DOI: 10.1111/j.1469-7610.2004.00374.x [PubMed: 15660640]

Butterworth B. 2010; Foundational numerical capacities and the origins of dyscalculia. Trends in Cognitive Sciences. 14(12):534-541.https://doi.org/10.1016/j.tics.2010.09.007 [PubMed: 20971676]

Cain K, Oakhill J, Bryant P. 2004; Children's reading comprehension ability: Concurrent prediction by working memory, verbal ability, and component skills. Journal of Educational Psychology. 96(1): 31.http://dx.doi.org/10.1037/0022-0663.96.1.31

Carretti B, Borella E, Cornoldi C, De Beni R. 2009; Role of working memory in explaining the performance of individuals with specific reading comprehension difficulties: A meta-analysis. Learning and Individual Differences. 19(2):246-251.https://doi.org/10.1016/j.lindif.2008.10.002

Chall, JS. Stages of reading development. New York, NY: McGraw-Hill; 1983.

Chen Q, Li J. 2014; Association between individual differences in non-symbolic number acuity and math performance: A meta-analysis. Acta Psychologica. 148:163-172.https://doi.org/10.1016/ j.actpsy.2014.01.016 [PubMed: 24583622] 
Child, AE; Cirino, PT; Fletcher, JM; Willcutt, EG; Fuchs, LS. A cognitive dimensional approach to understanding shared and unique cognitions relating to reading, math, and attentional skills. Journal of Learning Disabilities. https://doi.org/10.1177/0022219418775115(in press)

Cirino PT. 2011; The interrelationships of mathematical precursors in kindergarten. Journal of Experimental Child Psychology. 108:713-733.https://doi.org/10.1016/j.jecp.2010.11.004 [PubMed: 21194711]

Cirino PT, Fletcher JM, Ewing-Cobbs L, Barnes MA, Fuchs LS. 2007; Cognitive arithmetic differences in learning difficulty groups and the role of behavioral inattention. Learning Disabilities Research \& Practice. 22(1):25-35. DOI: 10.1111/j.1540-5826.2007.00228.x

Cirino PT, Fuchs LS, Elias JT, Powell SR, Schumacher RF. 2015; Cognitive and mathematical profiles for different forms of learning difficulties. Journal of Learning Disabilities. 48(2):156-175.https:// doi.org/10.1177/0022219413494239 [PubMed: 23851137]

Cirino PT, Miciak J, Ahmed Y, Barnes Marcia A, Taylor WP, Gerst EH. 2018Executive function: Association with multiple reading skills.

Claessens A, Dowsett C. 2014; Growth and change in attention problems, disruptive behavior, and achievement from kindergarten to fifth grade. Psychological Science. 25(12):2241-2251.https:// doi.org/10.1177/0956797614554265 [PubMed: 25376191]

Clarke B, Shinn MR. 2004; A preliminary investigation into the identification and development of early mathematics curriculum-based measurement. School Psychology Review. 33(2):234-248.

Cutting LE, Scarborough HS. 2006; Prediction of reading comprehension: Relative contributions of word recognition, language proficiency, and other cognitive skills can depend on how comprehension is measured. Scientific Studies of Reading. 10(3):277-299.http://dx.doi.org/ 10.1207/s1532799xssr1003_5

De Weerdt F, Desoete A, Roeyers H. 2013; Working memory in children with reading disabilities and/or mathematical disabilities. Journal of Learning Disabilities. 46(5):461-472.https://doi.org/ 10.1177/0022219412455238 [PubMed: 22941463]

Denckla MB, Rudel RG. 1976; Rapid 'automatized'naming (RAN): Dyslexia differentiated from other learning disabilities. Neuropsychologia. 14(4):471-479.https://doi.org/ 10.1016/0028-3932(76)90075-0 [PubMed: 995240]

Duncan GJ, Dowsett CJ, Claessens A, Magnuson K, Huston AC, Klebanov P, Brooks-Gunn J. 2007; School readiness and later achievement. Developmental Psychology. 43(6):1428.http://dx.doi.org/ 10.1037/0012-1649.43.6.1428 [PubMed: 18020822]

Friso-van den Bos I, van der Ven SH, Kroesbergen EH, van Luit JE. 2013; Working memory and mathematics in primary school children: A meta-analysis. Educational Research Review. 10:29_ 44.https://doi.org/10.1016/j.edurev.2013.05.003

Fuchs LS, Compton DL, Fuchs D, Paulsen K, Bryant JD, Hamlett CL. 2005; The prevention, identification, and cognitive determinants of math difficulty. Journal of Educational Psychology. 97(3):493.http://dx.doi.org/10.1037/0022-0663.97.3.493

Fuchs LS, Compton DL, Fuchs D, Powell SR, Schumacher RF, Hamlett CL, Vukovic RK. 2012; Contributions of domain-general cognitive resources and different forms of arithmetic development to pre-algebraic knowledge. Developmental Psychology. 48(5):1315-1326. [PubMed: 22409764]

Fuchs LS, Fuchs D, Compton DL, Powell SR, Seethaler PM, Capizzi AM, Fletcher JM. 2006; The cognitive correlates of third-grade skill in arithmetic, algorithmic computation, and arithmetic word problems. Journal of Educational Psychology. 98(1):29.http://dx.doi.org/ 10.1037/0022-0663.98.1.29

Fuchs LS, Fuchs D, Stuebing K, Fletcher JM, Hamlett CL, Lambert W. 2008; Problem solving and computational skill: Are they shared or distinct aspects of mathematical cognition? Journal of Educational Psychology. 100(1):30.http://dx.doi.org/10.1037/0022-0663.100.1.30 [PubMed: 20057912]

Fuchs LS, Geary DC, Compton DL, Fuchs D, Hamlett CL, Seethaler PM, Schatschneider C. 2010; Do different types of school mathematics development depend on different constellations of numerical versus general cognitive abilities? Developmental Psychology. 46(6):1731.http://dx.doi.org/ 10.1037/a0020662 [PubMed: 20822213] 
Fuchs LS, Geary DC, Fuchs D, Compton DL, Hamlett CL. 2016; Pathways to third-grade calculation versus word-reading competence: Are they more alike or different? Child Development. 87(2): 558-567. DOI: 10.1111/cdev.12474 [PubMed: 26700885]

Geary DC. 1993; Mathematical disabilities: cognitive, neuropsychological, and genetic components. Psychological Bulletin. 114(2):345. [PubMed: 8416036]

Geary DC. 2004; Mathematics and learning disabilities. Journal of Learning Disabilities. 37(1):415.https://doi.org/10.1177/00222194040370010201 [PubMed: 15493463]

Geary DC. 2011; Cognitive predictors of achievement growth in mathematics: a 5-year longitudinal study. Developmental Psychology. 47(6):1539.http://dx.doi.org/10.1037/a0025510 [PubMed: 21942667]

Geary DC, Bow-Thomas CC, Yao Y. 1992; Counting knowledge and skill in cognitive addition: A comparison of normal and mathematically disabled children. Journal of Experimental Child Psychology. 54(3):372-391.https://doi.org/10.1016/0022-0965(92)90026-3 [PubMed: 1453139]

Geary DC, Brown SC, Samaranayake VA. 1991; Cognitive addition: A short longitudinal study of strategy choice and speed-of-processing differences in normal and mathematically disabled children. Developmental Psychology. 27(5):787-797.http://doi.org/10.1037//0012-1649.27.5.787

Geary DC, Hamson CO, Hoard MK. 2000; Numerical and arithmetical cognition: A longitudinal study of process and concept deficits in children with learning disability. Journal of Experimental Child Psychology. 77(3):236-63.http://doi.org/10.1006/jecp.2000.2561 [PubMed: 11023658]

Geary DC, Hoard MK, Byrd-Craven J, Nugent L, Numtee C. 2007; Cognitive mechanisms underlying achievement deficits in children with mathematical learning disability. Child Development. 78(4): 1343-1359. DOI: 10.1111/j.1467-8624.2007.01069.x [PubMed: 17650142]

Geary DC, Hoard MK, Hamson CO. 1999; Numerical and arithmetical cognition: Patterns of functions and deficits in children at risk for a mathematical disability. Journal of Experimental Child Psychology. 74(3):213-239.https://doi.org/10.1006/jecp.1999.2515 [PubMed: 10527555]

Geary DC, Nicholas A, Li Y, Sun J. 2017; Developmental change in the influence of domain-general abilities and domain-specific knowledge on mathematics achievement: An eight-year longitudinal study. Journal of Educational Psychology. 109(5):680.http://dx.doi.org/10.1037/edu0000159 [PubMed: 28781382]

Geary DC, vanMarle K. 2016; Young children's core symbolic and nonsymbolic quantitative knowledge in the prediction of later mathematics achievement. Developmental Psychology. 52(12):2130-2144.http://dx.doi.org/10.1037/dev0000214 [PubMed: 27736101]

Georgiou GK, Parrila R, Kirby JR, Stephenson K. 2008; Rapid naming components and their relationship with phonological awareness, orthographic knowledge, speed of processing, and different reading outcomes. Scientific Studies of Reading. 12(4):325-350.http://dx.doi.org/ 10.1080/10888430802378518

Gerst EH, Cirino PT, Miciak J, Woods SP, Yoshida H, Gibbs MC. 2018The structure of processing speed in children and its impact on reading.

Gersten R, Chard D. 1999; Number sense rethinking arithmetic instruction for students with mathematical disabilities. The Journal of Special Education. 33(1):18-28.https://doi.org/ $10.1177 / 002246699903300102$

Good, RH, Gruba, J, Kaminski, RA. Best practices in using Dynamic Indicators of Basic Early Literacy Skills (DIBELS) in an outcomes-driven model. In: Thomas, A, Grimes, J, editorsBest Practices in School Psychology IV. Washington, DC: National Association of School Psychologists; 2002. 699-720.

Grills-Taquechel AE, Fletcher JM, Vaughn SR, Denton CA, Taylor P. 2013; Anxiety and inattention as predictors of achievement in early elementary school children. Anxiety, Stress \& Coping. 26(4): 391-410.http://dx.doi.org/10.1080/10615806.2012.691969

Halberda J, Mazzocco MM, Feigenson L. 2008; Individual differences in non-verbal number acuity correlate with maths achievement. Nature. 455:7213-668. 665-668. DOI: 10.1038/nature07246

Hanich LB, Jordan NC, Kaplan D, Dick J. 2001; Performance across different areas of mathematical cognition in children with learning difficulties. Journal of Educational Psychology. 93(3): 615.http://dx.doi.org/10.1037/0022-0663.93.3.615 
Hassinger-Das B, Jordan NC, Glutting J, Irwin C, Dyson N. 2014; Domain-general mediators of the relation between kindergarten number sense and first-grade mathematics achievement. Journal of Experimental Child Psychology. 118:78-92.https://doi.org/10.1016/j.jecp.2013.09.008 [PubMed: 24237789]

Hecht SA, Torgesen JK, Wagner RK, Rashotte CA. 2001; The relations between phonological processing abilities and emerging individual differences in mathematical computation skills: A longitudinal study from second to fifth grades. Journal of Experimental Child Psychology. 79(2): 192-227.https://doi.org/10.1006/jecp.2000.2586 [PubMed: 11343408]

Hollands FM, Pan Y, Shand R, Cheng H, Levin HM, Belfield CR, Hanisch-Cerda B. 2013Improving early literacy: cost-effectiveness analysis of effective reading programs. New York, NY: Center for Benefit-Cost Studies of Education, Teachers College, Columbia University.

Holloway ID, Ansari D. 2009; Mapping numerical magnitudes onto symbols: The numerical distance effect and individual differences in children's mathematics achievement. Journal of Experimental Child Psychology. 103(1):17-29.https://doi.org/10.1016/j.jecp.2008.04.001 [PubMed: 18513738]

Holloway ID, Battista C, Vogel SE, Ansari D. 2013; Semantic and perceptual processing of number symbols: evidence from a cross-linguistic fMRI adaptation study. Journal of Cognitive Neuroscience. 25(3):388-400. [PubMed: 23163414]

Hulme, C, Snowling, MJ. Developmental disorders of language learning and cognition. John Wiley \& Sons; 2009.

Jordan NC, Glutting J, Ramineni C. 2010; The importance of number sense to mathematics achievement in first and third grades. Learning and Individual Differences. 20(2):82-88.https:// doi.org/10.1016/j.lindif.2009.07.004 [PubMed: 20401327]

Jordan NC, Hanich LB. 2000; Mathematical thinking in second-grade children with different forms of LD. Journal of Learning Disabilities. 33(6):567-578.https://doi.org/10.1177/002221940003300605 [PubMed: 15495398]

Jordan NC, Hanich LB. 2003; Characteristics of children with moderate mathematics deficiencies: A longitudinal perspective. Learning Disabilities Research \& Practice. 18(4):213-221. DOI: 10.1111/1540-5826.00076

Jordan NC, Hanich LB, Kaplan D. 2003; A longitudinal study of mathematical competencies in children with specific mathematics difficulties versus children with comorbid mathematics and reading difficulties. Child Development. 74(3):834-850. DOI: 10.1111/1467-8624.00571 [PubMed: 12795393]

Jordan NC, Kaplan D, Hanich LB. 2002; Achievement growth in children with learning difficulties in mathematics: Findings of a two-year longitudinal study. Journal of Educational Psychology. 94(3): 586.http://dx.doi.org/10.1037/0022-0663.94.3.586

Kao G, Thompson JS. 2003; Racial and ethnic stratification in educational achievement and attainment. Annual Review of Sociology. 292003; :417-442. DOI: 10.1146/annurev.soc. 29.010202.100019

Kaufman, AS, Kaufman, NL. Kaufman Brief Intelligence Test - 2. Circle Pines: AGS Publishing; 2004.

Koponen T, Aunola K, Ahonen T, Nurmi J-E. 2007; Cognitive predictors of single-digit and procedural calculation skills and their covariation with reading skill. Journal of Experimental Child Psychology. 97(3):220-241.https://doi.org/10.1016/j.jecp.2007.03.001 [PubMed: 17560969]

Koponen T, Salmi P, Eklund K, Aro T. 2013; Counting and RAN: Predictors of arithmetic calculation and reading fluency. Journal of Educational Psychology. 105(1):162.http://dx.doi.org/10.1037/ a0029285

Korpipaa H, Koponen T, Aro T, Tolvanen A, Aunola K, Poikkeus A-M, Lerkkanen MK, Nurmi J-E. 2017; Covariation between reading and arithmetic skills from Grade 1 to Grade 7. Contemporary Educational Psychology. 51:131-140.

Kovas Y, Haworth CM, Harlaar N, Petrill SA, Dale PS, Plomin R. 2007; Overlap and specificity of genetic and environmental influences on mathematics and reading disability in 10-year-old twins. Journal of Child Psychology and Psychiatry. 48(9):914-922. DOI: 10.1111/j. 1469-7610.2007.01748..x [PubMed: 17714376] 
Krajewski K, Schneider W. 2009; Exploring the impact of phonological awareness, visual-spatial working memory, and preschool quantity-number competencies on mathematics achievement in elementary school: Findings from a 3-year longitudinal study. Journal of Experimental Child Psychology. 103(4):516-531.https://doi.org/10.1016/j.jecp.2009.03.009 [PubMed: 19427646]

Ladson-Billings G, Madison W. 1997; It doesn't add up: African American students' mathematics achievement. Journal for Research in Mathematics Education. 28(6):697-708. DOI: $10.2307 / 749638$

Landerl K, Moll K. 2010; Comorbidity of learning disorders: prevalence and familial transmission. Journal of Child Psychology and Psychiatry. 51(3):287-294. DOI: 10.1111/j. 1469-7610.2009.02164.x [PubMed: 19788550]

LeFevre JA, Fast L, Skwarchuk SL, Smith-Chant BL, Bisanz J, Kamawar D, Penner-Wilger M. 2010; Pathways to mathematics: Longitudinal predictors of performance. Child Development. 81(6): 1753-1767. DOI: 10.1111/j.1467-8624.2010.01508.x [PubMed: 21077862]

LeFevre J-A, Smith-Chant BL, Fast L, Skwarchuk S-L, Sargla E, Arnup JS, Kamawar D. 2006; What counts as knowing? The development of conceptual and procedural knowledge of counting from kindergarten through Grade 2. Journal of Experimental Child Psychology. 93(4):285-303.https:// doi.org/10.1016/j.jecp.2005.11.002 [PubMed: 16360166]

Lembke E, Foegen A. 2009; Identifying early numeracy indicators for kindergarten and first-grade students. Learning Disabilities Research \& Practice. 24(1):12-20.http://doi.org/10.1111/j. 1540-5826.2008.01273.x

Leppänen U, Aunola K, Niemi P, Nurmi J-E. 2008; Letter knowledge predicts Grade 4 reading fluency and reading comprehension. Learning and Instruction. 18(6):548-564.https://doi.org/10.1016/ j.learninstruc.2007.11.004

Liberman IY, Shankweiler D, Fischer FW, Carter B. 1974; Explicit syllable and phoneme segmentation in the young child. Journal of Experimental Child Psychology. 18(2):201-212.https://doi.org/ 10.1016/0022-0965(74)90101-5

Liberman IY, Shankweiler D, Liberman AM. 1989The alphabetic principle and learning to read.

Lonigan CJ, Burgess SR, Anthony JL. 2000; Development of emergent literacy and early reading skills in preschool children: evidence from a latent-variable longitudinal study. Developmental Psychology. 36(5):596.http://dx.doi.org/10.1037/0012-1649.36.5.596 [PubMed: 10976600]

Locascio G, Mahone EM, Eason SH, Cutting LE. 2010; Executive dysfunction among children with reading comprehension deficits. Journal of Learning Disabilities. 43(5):441-454.https://doi.org/ 10.1177/0022219409355476 [PubMed: 20375294]

Lubienski ST. 2002; A closer look at black-white mathematics gaps: Intersections of race and SES in NAEP achievement and instructional practices data. The Journal of Negro Education. 71(4):269287. DOI: $10.2307 / 3211180$

Martin RB, Cirino PT, Barnes MA, Sharp C. 2014; Number and counting skills in kindergarten as predictors of grade 1 mathematical skills. Learning and Individual Differences. 34:12-23.https:// doi.org/10.1016/j.lindif.2014.05.006 [PubMed: 25089081]

Mazzocco MM, Grimm KJ. 2013; Growth in rapid automatized naming from grades K to 8 in children with math or reading disabilities. Journal of Learning Disabilities. 46(6):517-533.https://doi.org/ 10.1177/0022219413477475 [PubMed: 23449728]

McGraw R, Lubienski S, Strutchens M. 2006; A closer look at gender in NAEP mathematics achievement and affect data: Intersections with achievement, race/ethnicity, and socioeconomic status. National Council of Teachers of Mathematics. 37(2):129-150. DOI: 10.2307/30034845

Moll K, Göbel SM, Gooch D, Landerl K, Snowling MJ. 2016; Cognitive risk factors for specific learning disorder: Processing speed, temporal processing, and working memory. Journal of Learning Disabilities. 49(3):272-281.https://doi.org/10.1177/0022219414547221 [PubMed: 25124507]

Moll K, Göbel SM, Snowling MJ. 2015; Basic number processing in children with specific learning disorders: comorbidity of reading and mathematics disorders. Child Neuropsychology. 21(3):399417.https://doi.org/10.1177/0022219413477475 [PubMed: 24697279] 
Monette S, Bigras M, Guay M-C. 2011; The role of the executive functions in school achievement at the end of Grade 1. Journal of Experimental Child Psychology. 109(2):158-173.https://doi.org/ 10.1016/j.jecp.2011.01.008 [PubMed: 21349537]

Ostad SA. 2013; Private speech use in arithmetical calculation: Contributory role of phonological awareness in children with and without mathematical difficulties. Journal of Learning Disabilities. 46(4):291-303.https://doi.org/10.1177/0022219411419013 [PubMed: 22134964]

Passolunghi MC, Vercelloni B, Schadee H. 2007; The precursors of mathematics learning: Working memory, phonological ability and numerical competence. Cognitive Development. 22(2):165184.https://doi.org/10.1016/j.cogdev.2006.09.001

Pearson, NCS. AIMSweb technical manual. Bloomington, MN: Author; 2012.

Pennington BF. 2006; From single to multiple deficit models of developmental disorders. Cognition. 101(2):385-413.https://doi.org/10.1016/j.jecp.2011.01.008 [PubMed: 16844106]

Peterson RL, Boada R, McGrath LM, Willcutt EG, Olson RK, Pennington BF. 2016; Cognitive prediction of reading, math, and attention: Shared and unique influences. Journal of Learning Disabilities. 50(4):408-421.https://doi.org/10.1177/0022219415618500 [PubMed: 26825667]

Pham AV. 2016; Differentiating behavioral ratings of inattention, impulsivity, and hyperactivity in children: effects on reading achievement. Journal of attention disorders. 20(8):674-683.https:// doi.org/10.1177/1087054712473833 [PubMed: 23400214]

Resnick LB. 1989; Developing mathematical knowledge. American Psychologist. 44(2):162-169.

Reynolds, CR, Bigler, ED. Test of Memory and Learning: TOMAL. Austin, TX: Pro-ed; 1994.

Reynolds AJ, Temple JA. 2008; Cost-effective early childhood development programs from preschool to third grade. Annu. Rev. Clin. Psychol. 4:109-139. [PubMed: 18370615]

Riley, MS, Greeno, JG, Heller, J. The development of children's problem solving ability in arithmetic. In: Ginsburg, H, editorThe development of mathematical thinking. New York, NY: Academic Press; 1983. 153-196.

Robinson CS, Menchetti BM, Torgesen JK. 2002; Toward a Two-Factor Theory of One Type of Mathematics Disabilities. Learning Disabilities Research \& Practice. 17(2):81-89. DOI: 10.1111/1540-5826.00035

Savage R, Lavers N, Pillay V. 2007; Working memory and reading difficulties: What we know and what we don't know about the relationship. Educational Psychology Review. 19(2):185.doi: 10.1007/s10648-006-9024-1

Scarborough HS. 1998; Predicting the future achievement of second graders with reading disabilities: Contributions of phonemic awareness, verbal memory, rapid naming, and IQ. Annals of Dyslexia. 48(1):115-136.

Schatschneider C, Fletcher JM, Francis DJ, Carlson CD, Foorman BR. 2004; Kindergarten prediction of reading skills: A longitudinal comparative analysis. Journal of Educational Psychology. 96(2): 265.http://dx.doi.org/10.1037/0022-0663.96.2.265

Schneider M, Beeres K, Coban L, Merz S, Susan Schmidt S, Stricker J, De Smedt B. 2017; Associations of non-symbolic and symbolic numerical magnitude processing with mathematical competence: A meta-analysis. Developmental Science. 20:3.doi: 10.1111/desc.12372

Shanahan MA, Pennington BF, Yerys BE, Scott A, Boada R, Willcutt EG, DeFries JC. 2006; Processing speed deficits in attention deficit/hyperactivity disorder and reading disability. Journal of Abnormal Child Psychology. 34(5):584.

Shinn, MR, Shinn, MM. AIMSweb training workbook: Administration and scoring of reading curriculum-based measurement (R-CBM) for use in general outcome measurement. Eden Prarie, MN: Edformation Inc; 2002. Retrieved from http://www.kunaschools.org/resources/documents/ AdminandScoringR-CBM09292005.pdf

Siegel LS, Ryan EB. 1989; The development of working memory in normally achieving and subtypes of learning disabled children. Child Development. :973-980. DOI: 10.2307/1131037 [PubMed: 2758890]

Steele A, Karmiloff-Smith A, Cornish K, Scerif G. 2012; The multiple subfunctions of attention: differential developmental gateways to literacy and numeracy. Child Development. 83(6):20282041. DOI: 10.1111/j.1467-8624.2012.01809.x [PubMed: 22804751] 
Sulzby, E. Children's emergent reading of favorite storybooks: A developmental study; Reading Research Quarterly. 1985. 458-481. Retrieved from http://www.jstor.org/stable/747854

Swanson HL, Beebe-Frankenberger M. 2004; The relationship between working memory and mathematical problem solving in children at risk and not at risk for serious math difficulties. Journal of Educational Psychology. 96(3):471.http://dx.doi.org/10.1037/0022-0663.96.3.471

Swanson HL, Jerman O. 2006; Math disabilities: A selective meta-analysis of the literature. Review of Educational Research. 76(2):249-274.https://doi.org/10.3102/00346543076002249

Swanson HL, Orosco MJ, Kudo M. 2017; Does growth in the executive system of working memory underlie growth in literacy for bilingual children with and without reading disabilities? Journal of Learning Disabilities. 50(4):386-407.https://doi.org/10.1177/0022219415618499 [PubMed: 26712798]

Swanson JM, Schuck S, Porter MM, Hartman CA, Sergeant JA, Clevenger W, Wigal T. 2012; Categorical and dimensional definitions and evaluations of symptoms of ADHD: History of the SNAP and the SWAN rating scales. International Journal of Educational and Psychological Assessment. 10(1):51-70. [PubMed: 26504617]

Tate WF. 1997; Race-ethnicity, SES, Gender, and language proficiency trends in mathematics achievement: An update. Journal of Research in Mathematics Education. 28(6):652-679. DOI: $10.2307 / 749636$

Torgesen, J, Wagner, R, Rashotte, C. Test of Word Reading Efficiency. Austin, TX: Pro-Ed; 1999.

University of Oregon Center on Teaching and Learning. UO DIBELS Data System. (n.d.). Retrieved July 26, 2017, from https://dibels.uoregon.edu/

van der Sluis S, de Jong PF, van der Leij A. 2004; Inhibition and shifting in children with learning deficits in arithmetic and reading. Journal of Experimental Child Psychology. 87(3):239266.https://doi.org/10.1016/j.jecp.2003.12.002 [PubMed: 14972600]

Vanbinst K, Ansari D, Ghesquière P, De Smedt B. 2016; Symbolic numerical magnitude processing is as important to arithmetic as phonological awareness is to reading. PloS one. 11(3):e0151045.https://doi.org/10.1371/journal.pone.0151045 [PubMed: 26942935]

Vellutino FR, Fletcher JM, Snowling MJ, Scanlon DM. 2004; Specific reading disability (dyslexia): what have we learned in the past four decades? Journal of Child Psychology and Psychiatry. 45(1):2-40. DOI: 10.1046/j.0021-9630.2003.00305.x [PubMed: 14959801]

Wagner RK, Torgesen JK. 1987; The nature of phonological processing and its causal role in the acquisition of reading skills. Psychological Bulletin. 101(2):192.http://dx.doi.org/ 10.1037/0033-2909.101.2.192

Wagner, RK, Torgesen, JK, Rashotte, CA. Comprehensive Test of Phonological Processing. Austin, TX: Pro-Ed; 1999.

White JL, Moffitt TE, Silva PA. 1992; Neuropsychological and socio-emotional correlates of specificarithmetic disability. Archives of Clinical Neuropsychology. 7(1):1-16.https://doi.org/10.1093/ $\operatorname{arclin} / 7.1 .1$ [PubMed: 14589674]

Whitehurst GJ, Lonigan CJ. 1998; Child development and emergent literacy. Child Development. 69(3):848-872. DOI: 10.1111/j.1467-8624.1998.tb06247.x [PubMed: 9680688]

Wilkinson, GS. Wide Range Achievement Test-Third Edition (WRAT-3). Wilmington, DE: Wide Range; 1993.

Willcutt, E, Sonuga-Barke, E, Nigg, J, Sergeant, J. Biological Child Psychiatry. Karger Publishers; 2008. Recent developments in neuropsychological models of childhood psychiatric disorders; 195-226.

Willcutt EG, Betjemann RS, McGrath LM, Chhabildas NA, Olson RK, DeFries JC, Pennington BF. 2010; Etiology and neuropsychology of comorbidity between RD and ADHD: The case for multiple-deficit models. Cortex. 46(10):1345-1361.https://doi.org/10.1016/j.cortex.2010.06.009 [PubMed: 20828676]

Willcutt EG, Petrill SA, Wu S, Boada R, DeFries JC, Olson RK, Pennington BF. 2013; Comorbidity between reading disability and math disability: Concurrent psychopathology, functional impairment, and neuropsychological functioning. Journal of Learning Disabilities. 46(6):500516.https://doi.org/10.1177/0022219413477476 [PubMed: 23449727] 
Wolf M, Bowers PG. 1999; The double-deficit hypothesis for the developmental dyslexias. Journal of Educational Psychology. 91(3):415.http://dx.doi.org/10.1037/0022-0663.91.3.415

Wolf M, Bowers PG, Biddle K. 2000; Naming-speed processes, timing, and reading A conceptual review. Journal of Learning Disabilities. 33(4):387-407.https://doi.org/ 10.1177/002221940003300409 [PubMed: 15493099]

Woodcock, R, McGrew, K, Mather, N. Woodcock-Johnson - III. Itasca, IL: Riverside Publishing; 2001.

Yovanoff P, Duesbery L, Alonzo J, Tindal G. 2005; Grade-level invariance of a theoretical causal structure predicting reading comprehension with vocabulary and oral reading fluency. Educational Measurement: Issues and Practice. 24(3):4-12. DOI: 10.1111/j. 1745-3992.2005.00014.x 


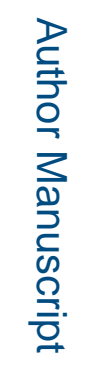
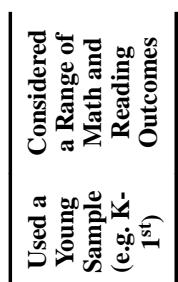

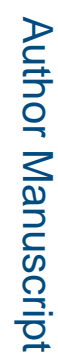

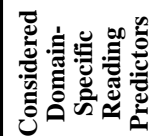

로을

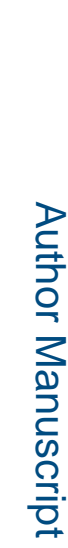

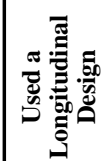

告

$\sin \left(\frac{\pi}{2}\right)$

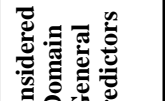

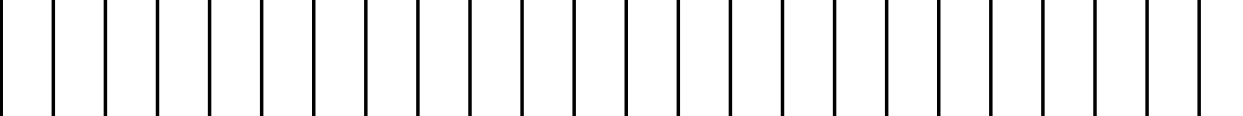

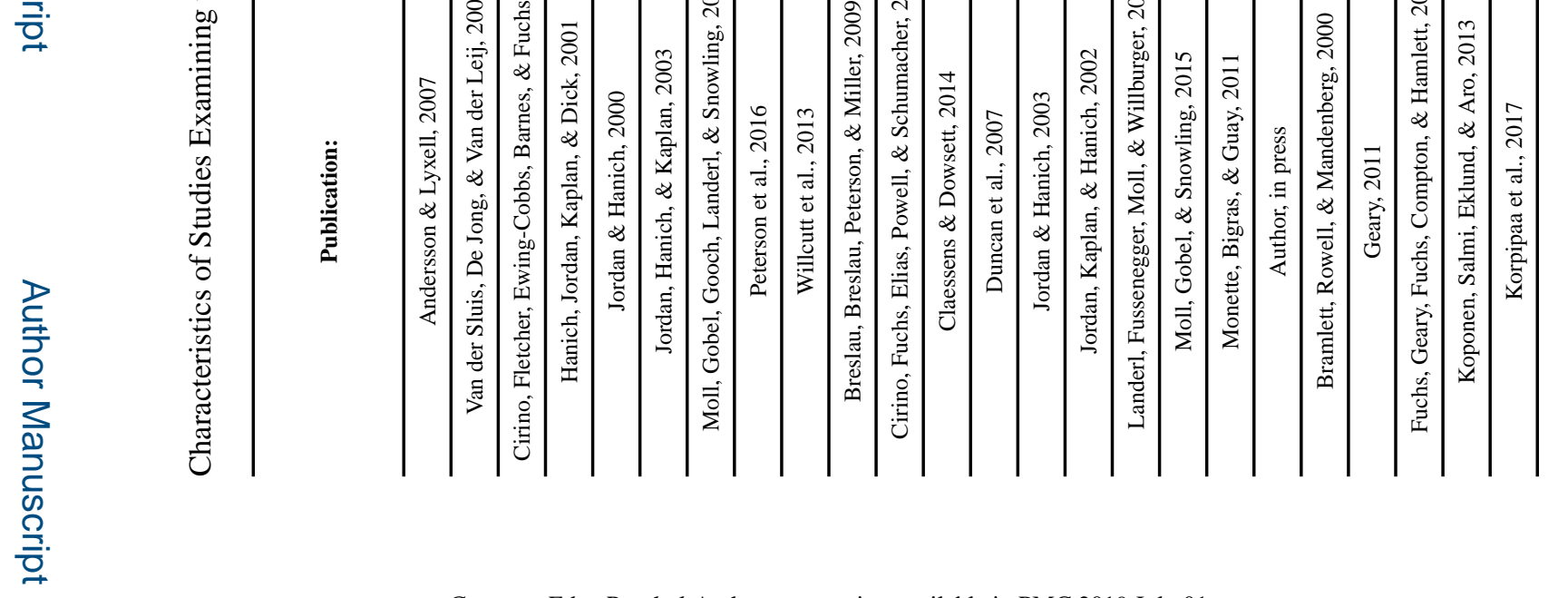

Contemp Educ Psychol. Author manuscript; available in PMC 2019 July 01. 


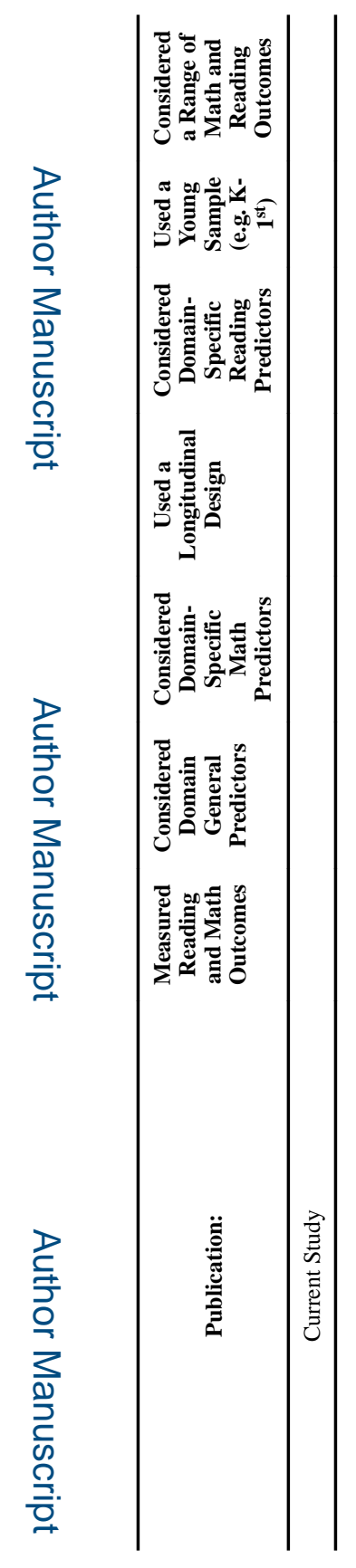

로을

Contemp Educ Psychol. Author manuscript; available in PMC 2019 July 01. 
Table 2

Task Reliabilities

\begin{tabular}{|c|c|c|c|c|}
\hline Domain & Construct & Task & Reliability & $\begin{array}{l}\text { Type of Reliability } \\
\text { and/or Reference }\end{array}$ \\
\hline \multirow{8}{*}{$\begin{array}{l}\text { Domain Specific Predictors: } \\
\text { Math }\end{array}$} & \multirow{3}{*}{ Rote Counting } & * Oral Counting & 0.99 & Clarke \& Shinn, 2004 \\
\hline & & Counting Down: 10 to 1 & \multirow[b]{2}{*}{0.54} & \multirow[b]{2}{*}{ Alternate Forms } \\
\hline & & Counting Down: 20 to 1 & & \\
\hline & \multirow{2}{*}{ Counting Knowledge } & Count Out Objects & 0.68 & Cronbach Alpha \\
\hline & & Puppet Counting & 0.80 & Cronbach Alpha \\
\hline & \multirow[b]{2}{*}{ Symbolic Comparison } & Comparing Numbers & 0.59 & Cronbach Alpha \\
\hline & & $\begin{array}{l}\text { *AIMSWeb Quantity } \\
\text { Discrimination }\end{array}$ & 0.85 to 0.93 & $\begin{array}{l}\text { Clarke \& Shinn, 2004 / } \\
\text { Lembke \& Foegen, } 2009\end{array}$ \\
\hline & Symbolic Labeling & Number Identification & 0.86 & Cronbach Alpha \\
\hline \multirow{6}{*}{$\begin{array}{l}\text { Domain Specific Predictors: } \\
\text { Reading }\end{array}$} & \multirow[t]{2}{*}{ Phonological Awareness } & ${ }^{\dagger}$ CTOPP Blending Words & $0.69 / 0.88$ & $\begin{array}{c}\text { Cronbach Alpha / } \\
\text { Wagner, Torgeson, and } \\
\text { Rashotte (1999) }\end{array}$ \\
\hline & & ${ }^{\dagger}$ CTOPP Elision & $0.69 / 0.88$ & $\begin{array}{l}\text { Cronbach Alpha / } \\
\text { Wagner et al. (1999) }\end{array}$ \\
\hline & \multirow{3}{*}{ Rapid Naming } & †CTOPP Rapid Digit Naming & \multirow{3}{*}{$\begin{array}{l}0.64 \text { to } 0.80 / \\
0.77 \text { to } 0.97\end{array}$} & \multirow{3}{*}{$\begin{array}{c}\text { Alternate Forms / } \\
\text { Wagner et al. (1999) }\end{array}$} \\
\hline & & ${ }^{\dagger}$ CTOPP Rapid Letter Naming & & \\
\hline & & †CTOPP Rapid Object Naming & & \\
\hline & Vocabulary & † KBIT-2 Vocabulary & $0.84 / 0.90$ & $\begin{array}{c}\text { Cronbach Alpha /Pearson } \\
\text { (2004) }\end{array}$ \\
\hline \multirow{4}{*}{ Domain General Predictors } & Working Memory & Spatial Working Memory & 0.74 & Cronbach Alpha \\
\hline & Inattention & SWAN Inattention & 0.98 & Cronbach Alpha \\
\hline & Processing Speed & Underlining Task: $(4 \mathrm{~s}$ and $+\mathrm{s})$ & 0.47 & Alternate Forms \\
\hline & Nonverbal Reasoning & ${ }^{\dagger}$ KBIT-2 Matrices & $0.88 / 0.86$ & $\begin{array}{c}\text { Cronbach Alpha /Pearson } \\
\text { (2004) }\end{array}$ \\
\hline \multirow{5}{*}{ Math Outcomes } & \multirow[t]{2}{*}{ Computation } & twJ-3 Calculations & $0.77 / 0.96$ & $\begin{array}{l}\text { Cronbach Alpha / } \\
\text { McGrew, Schrank, and } \\
\text { Woodcock (2007) }\end{array}$ \\
\hline & & ${ }^{\dagger}$ WRAT-3 Arithmetic & $0.73 / 0.87$ & $\begin{array}{l}\text { Cronbach Alpha / } \\
\text { Wilkinson (1993) }\end{array}$ \\
\hline & Math Fluency & $\begin{array}{l}\text { Small Sums Addition } \\
\text { Small Sums Subtraction }\end{array}$ & 0.80 & Alternate Forms \\
\hline & \multirow[t]{2}{*}{ Problem Solving } & ${ }^{\dagger}$ WJ-3 Applied Problems & $0.82 / 0.88$ & $\begin{array}{l}\text { Cronbach Alpha / } \\
\text { McGrew et al. (2007) }\end{array}$ \\
\hline & & Single Digit Story Problems & 0.85 & Cronbach Alpha \\
\hline \multirow[t]{3}{*}{ Reading Outcomes } & \multirow[t]{3}{*}{ Decoding } & $\begin{array}{l}\text { †WJ-3 Letter Word } \\
\text { Identification }\end{array}$ & $0.94 / 0.98$ & $\begin{array}{l}\text { Cronbach Alpha / } \\
\text { McGrew et al. (2007) }\end{array}$ \\
\hline & & ${ }^{\dagger}$ WJ-3 Word Attack & $0.91 / 0.94$ & $\begin{array}{l}\text { Cronbach Alpha / } \\
\text { McGrew et al. (2007) }\end{array}$ \\
\hline & & †WRAT-3 Reading & $0.95 / 0.95$ & $\begin{array}{l}\text { Cronbach Alpha / } \\
\text { Wilkinson (1993) }\end{array}$ \\
\hline
\end{tabular}

Contemp Educ Psychol. Author manuscript; available in PMC 2019 July 01. 


\begin{tabular}{|c|c|c|c|c|}
\hline Domain & Construct & Task & Reliability & $\begin{array}{l}\text { Type of Reliability } \\
\text { and/or Reference }\end{array}$ \\
\hline & Reading Fluency & $\begin{array}{l}\text { *TOWRE Sight Word } \\
\text { Efficiency }\end{array}$ & 0.97 & $\begin{array}{l}\text { Torgesen, Wagner, and } \\
\text { Rashotte (1999) }\end{array}$ \\
\hline & & $\begin{array}{l}\text { *DIBELs Oral Reading } \\
\text { Fluency }\end{array}$ & 0.92 to 0.97 & $\begin{array}{l}\text { University of Oregon } \\
\text { Center on Teaching and } \\
\text { Learning (n.d.) }\end{array}$ \\
\hline & Reading Comprehension & $\begin{array}{l}t \text { WJ-3 Passage } \\
\text { Comprehension }\end{array}$ & $0.89 / 0.96$ & $\begin{array}{l}\text { Cronbach Alpha / } \\
\text { McGrew et al. (2007) }\end{array}$ \\
\hline & & *AIMSWeb Mazes & 0.68 & Pearson (2012) \\
\hline
\end{tabular}

Note. For composites, reliabilities (coefficent alpha or alternate form) presented are for each individual measure that contribute to the composites, based on the sample.

*

For these measures, it is not possible to calculate sample reliabilities; in these cases, reliabilities from outside sources (e.g., publisher) are presented.

${ }^{\dagger}$ For these measures, because they are commonly used, both sample reliabilities, and publisher reliabilities, are reported. 


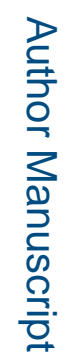

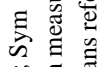

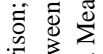

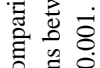

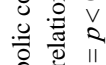

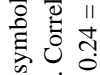

II

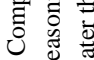

है

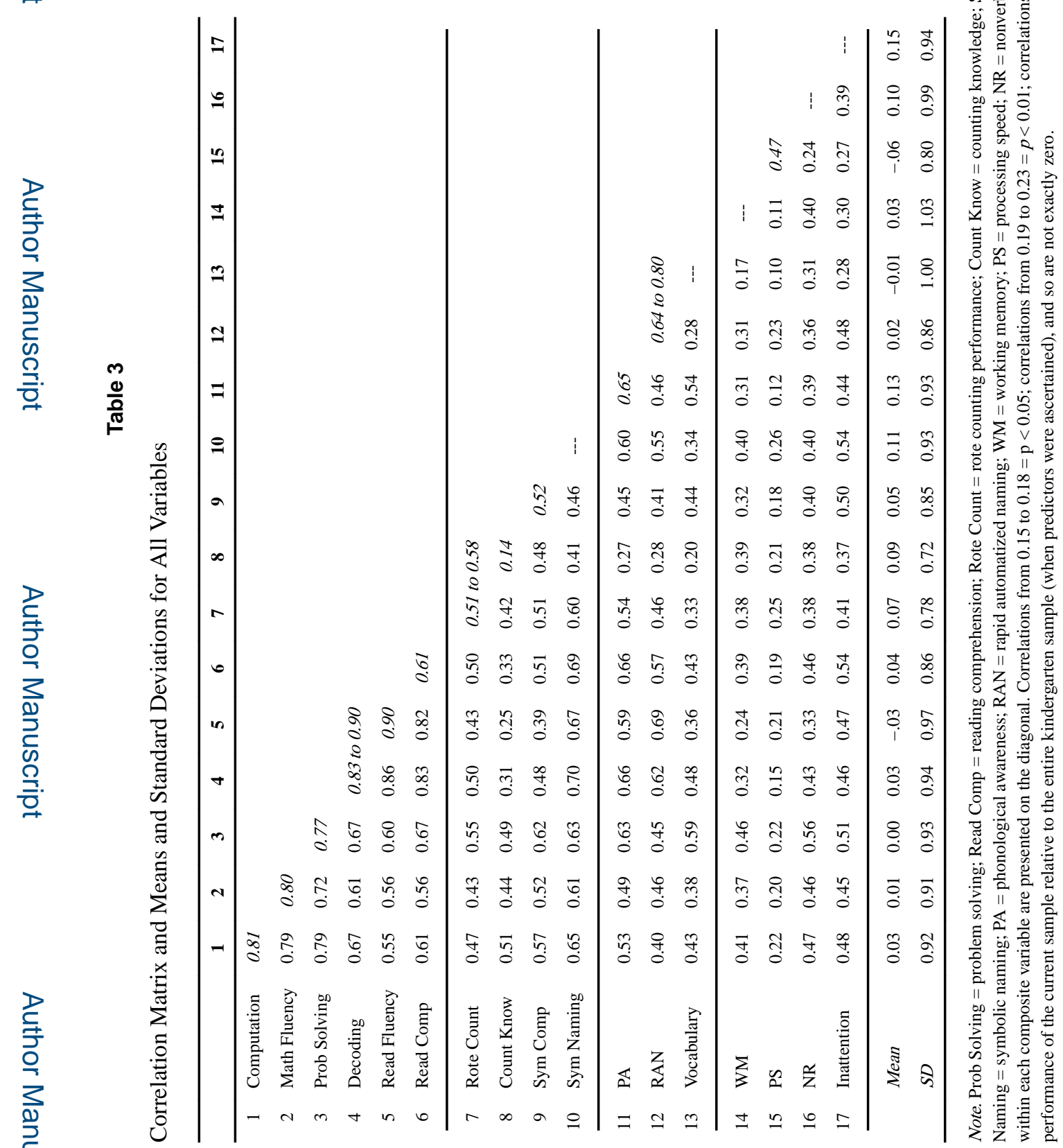

Contemp Educ Psychol. Author manuscript; available in PMC 2019 July 01. 


\section{Table 4}

\section{Multivariate Contrast Results}

\begin{tabular}{|c|c|c|c|c|}
\hline & & $\mathbf{F}$ & $\mathbf{p}$ & Wilks' $\wedge$ \\
\hline \multirow{3}{*}{ Rote Counting } & Decoding vs. Computation & 0.22 & 0.636 & 0.999 \\
\hline & Reading Fluency vs. Math Fluency & 0.07 & 0.794 & 1.000 \\
\hline & Reading Comprehension vs. Problem Solving & 0.57 & 0.451 & 0.996 \\
\hline \multirow{3}{*}{ Counting Knowledge } & Decoding vs. Computation & 6.50 & 0.012 & 0.961 \\
\hline & Reading Fluency vs. Math Fluency & 4.97 & 0.027 & 0.970 \\
\hline & Reading Comprehension vs. Problem Solving & 4.60 & 0.034 & 0.972 \\
\hline \multirow{3}{*}{ Symbolic Comparison } & Decoding vs. Computation & 3.04 & 0.083 & 0.981 \\
\hline & Reading Fluency vs. Math Fluency & 3.51 & 0.063 & 0.979 \\
\hline & Reading Comprehension vs. Problem Solving & 0.62 & 0.434 & 0.996 \\
\hline \multirow{3}{*}{ Symbolic Naming } & Decoding vs. Computation & 0.50 & 0.482 & 0.997 \\
\hline & Reading Fluency vs. Math Fluency & 0.02 & 0.896 & 1.000 \\
\hline & Reading Comprehension vs. Problem Solving & 2.11 & 0.149 & 0.987 \\
\hline \multirow{3}{*}{ Phonological Awareness } & Decoding vs. Computation & 5.07 & 0.026 & 0.969 \\
\hline & Reading Fluency vs. Math Fluency & 4.78 & 0.030 & 0.971 \\
\hline & Reading Comprehension vs. Problem Solving & 2.34 & 0.128 & 0.986 \\
\hline \multirow{3}{*}{ Rapid Naming } & Decoding vs. Computation & 16.46 & $<0.001$ & 0.907 \\
\hline & Reading Fluency vs. Math Fluency & 20.35 & $<0.001$ & 0.887 \\
\hline & Reading Comprehension vs. Problem Solving & 5.29 & 0.023 & 0.968 \\
\hline \multirow{3}{*}{ Vocabulary } & Decoding vs. Computation & 0.02 & 0.880 & 1.000 \\
\hline & Reading Fluency vs. Math Fluency & 0.95 & 0.331 & 0.994 \\
\hline & Reading Comprehension vs. Problem Solving & 10.02 & 0.002 & 0.941 \\
\hline \multirow{3}{*}{ Working Memory } & Decoding vs. Computation & 2.94 & 0.088 & 0.982 \\
\hline & Reading Fluency vs. Math Fluency & 2.42 & 0.122 & 0.985 \\
\hline & Reading Comprehension vs. Problem Solving & 2.50 & 0.116 & 0.985 \\
\hline \multirow{3}{*}{ Processing Speed } & Decoding vs. Computation & 0.83 & 0.363 & 0.995 \\
\hline & Reading Fluency vs. Math Fluency & 0.27 & 0.604 & 0.998 \\
\hline & Reading Comprehension vs. Problem Solving & 0.13 & 0.721 & 0.999 \\
\hline \multirow{3}{*}{ Nonverbal Reasoning } & Decoding vs. Computation & 0.54 & 0.465 & 0.997 \\
\hline & Reading Fluency vs. Math Fluency & 2.40 & 0.123 & 0.985 \\
\hline & Reading Comprehension vs. Problem Solving & 2.69 & 0.103 & 0.983 \\
\hline \multirow{3}{*}{ Attention } & Decoding vs. Computation & 1.00 & 0.318 & 0.994 \\
\hline & Reading Fluency vs. Math Fluency & 0.01 & 0.913 & 1.000 \\
\hline & Reading Comprehension vs. Problem Solving & 0.13 & 0.724 & 0.999 \\
\hline
\end{tabular}

Note. Bolded outcomes indicate which outcome was more strongly predicted by the cognitive variable for instances where the multivariate contrast was significant. 


\section{Table 5}

Partial Correlations, and Changes in $\mathrm{r}^{2}$ between Reading and Math Variables

\begin{tabular}{|c|c|c|c|c|}
\hline Partialled Variable & & $\begin{array}{l}\text { Decoding \& } \\
\text { Computation }\end{array}$ & $\begin{array}{l}\text { Reading Fluency } \\
\text { \& Math Fluency }\end{array}$ & $\begin{array}{c}\text { Reading } \\
\text { Comprehension } \\
\text { \& Problem } \\
\text { Solving }\end{array}$ \\
\hline & Zero order $r$ & 0.67 & 0.56 & 0.67 \\
\hline & $R^{2}$ & 0.44 & 0.32 & 0.45 \\
\hline \multirow{4}{*}{ Rote Counting } & $p r$ & 0.56 & 0.47 & 0.54 \\
\hline & $p r^{2}$ & 0.31 & 0.22 & 0.29 \\
\hline & $\%$ Change $R^{2}$ & -0.30 & -0.31 & -0.36 \\
\hline & $p r$ & 0.62 & 0.52 & 0.62 \\
\hline \multirow[t]{3}{*}{ Counting Knowledge } & $p r^{2}$ & 0.39 & 0.27 & 0.38 \\
\hline & $\%$ Change $R^{2}$ & -0.11 & -0.16 & -0.16 \\
\hline & $p r$ & 0.54 & 0.46 & 0.53 \\
\hline \multirow[t]{3}{*}{ Symbolic Comparison } & $p r^{2}$ & 0.30 & 0.21 & 0.28 \\
\hline & $\%$ Change $R^{2}$ & -0.32 & -0.34 & -0.38 \\
\hline & $p r$ & 0.39 & 0.28 & 0.42 \\
\hline \multirow[t]{3}{*}{ Symbolic Naming } & $p r^{2}$ & 0.15 & 0.08 & 0.18 \\
\hline & $\%$ Change $R^{2}$ & -0.66 & -0.75 & -0.60 \\
\hline & $p r$ & 0.48 & 0.39 & 0.43 \\
\hline \multirow[t]{3}{*}{ Phonological Awareness } & $p r^{2}$ & 0.23 & 0.15 & 0.18 \\
\hline & $\%$ Change $R^{2}$ & -0.48 & -0.53 & -0.60 \\
\hline & $p r$ & 0.57 & 0.40 & 0.56 \\
\hline \multirow[t]{3}{*}{ Rapid Naming } & $p r^{2}$ & 0.33 & 0.16 & 0.31 \\
\hline & $\%$ Change $R^{2}$ & -0.25 & -0.50 & -0.31 \\
\hline & $p r$ & 0.58 & 0.50 & 0.58 \\
\hline \multirow[t]{3}{*}{ Vocabulary } & $p r^{2}$ & 0.33 & 0.25 & 0.34 \\
\hline & $\%$ Change $R^{2}$ & -0.25 & -0.22 & -0.24 \\
\hline & $p r$ & 0.62 & 0.53 & 0.60 \\
\hline \multirow[t]{3}{*}{ Working Memory } & $p r^{2}$ & 0.39 & 0.28 & 0.36 \\
\hline & $\%$ Change $R^{2}$ & -0.11 & -0.13 & -0.20 \\
\hline & $p r$ & 0.65 & 0.55 & 0.66 \\
\hline \multirow[t]{3}{*}{ Processing Speed } & $p r^{2}$ & 0.42 & 0.30 & 0.43 \\
\hline & $\%$ Change $R^{2}$ & -0.05 & -0.06 & -0.04 \\
\hline & $p r$ & 0.59 & 0.50 & 0.56 \\
\hline \multirow[t]{3}{*}{ Nonverbal Reasoning } & $p r^{2}$ & 0.35 & 0.25 & 0.32 \\
\hline & $\%$ Change $R^{2}$ & -0.20 & -0.22 & -0.29 \\
\hline & $p r$ & 0.57 & 0.45 & 0.55 \\
\hline \multirow[t]{2}{*}{ Attention } & $p r^{2}$ & 0.33 & 0.20 & 0.30 \\
\hline & $\%$ Change $R^{2}$ & -0.25 & -0.38 & -0.33 \\
\hline Partialling All & $p r$ & 0.33 & 0.23 & 0.21 \\
\hline
\end{tabular}

Contemp Educ Psychol. Author manuscript; available in PMC 2019 July 01. 


\begin{tabular}{|c|c|c|c|c|}
\hline Partialled Variable & & $\begin{array}{c}\text { Decoding \& } \\
\text { Computation }\end{array}$ & $\begin{array}{l}\text { Reading Fluency } \\
\text { \& Math Fluency }\end{array}$ & $\begin{array}{c}\text { Reading } \\
\text { Comprehension } \\
\text { \& Problem } \\
\text { Solving }\end{array}$ \\
\hline & $p r^{2}$ & 0.11 & 0.05 & 0.04 \\
\hline & $\%$ Change $R^{2}$ & -0.75 & -0.84 & -0.91 \\
\hline \multicolumn{5}{|l|}{ Post-Hoc Analyses } \\
\hline \multirow{3}{*}{ Partialling Sym Nam, PA, RAN } & $p r$ & 0.34 & 0.18 & 0.29 \\
\hline & $p r^{2}$ & 0.12 & 0.03 & 0.08 \\
\hline & $\%$ Change $R^{2}$ & -0.73 & -0.91 & -0.82 \\
\hline \multirow{3}{*}{ Partialling Sym Nam, PA, RAN, Count Know, Atten, NVR } & $p r$ & 0.36 & 0.21 & 0.24 \\
\hline & $p r^{2}$ & 0.13 & 0.05 & 0.06 \\
\hline & $\%$ Change $R^{2}$ & -0.70 & -0.84 & -0.87 \\
\hline
\end{tabular}

Note. Sym nam = symbolic naming; PA = phonological awareness; RAN = rapid automatized naming; count know = counting knowledge; atten = attention; NVR = nonverbal reasoning. $p<0.05$ for correlations from 0.15 to $0.18 ; p<0.01$ for correlations from 0.19 to $0.23 ; p<0.001$ for correlations greater than $0.24 . R^{2}=$ squared correlation, or proportion of variance shared; $p r=$ partial correlation; $p r^{2}=$ squared partial correlation, or proportion of variance shared after controlling for cognitive predictor variable; \% Change in $R^{2}=\left(\left(p r^{2}-R^{2}\right) / R^{2}\right)$, or the relative reduction in variance attributed to the cognitive predictor variable; this value is labeled with a minus sign because it reflects a decrease in relative variance. The absolute reduction in $R^{2}$ is not shown, but can be computed by subtracting the values in the $p r^{2}$ row from those of row 2 (original $R^{2}$ ) within a given column. "Partialling All" indicates that all predictor variables were partialled simultaneously to ascertain the total amount of shared variance accounted for by the entire collection of predictors. Similarly, "Partialling Symbolic Naming, PA, RAN" indicates that these three cognitive variables were partialled simultaneously, and "Partialling Sym Nam, PA, RAN, Count Know, Atten, NVR" indicates that these six cognitive variables were partialled simultaneously. 